Biotechnology for Biofuels

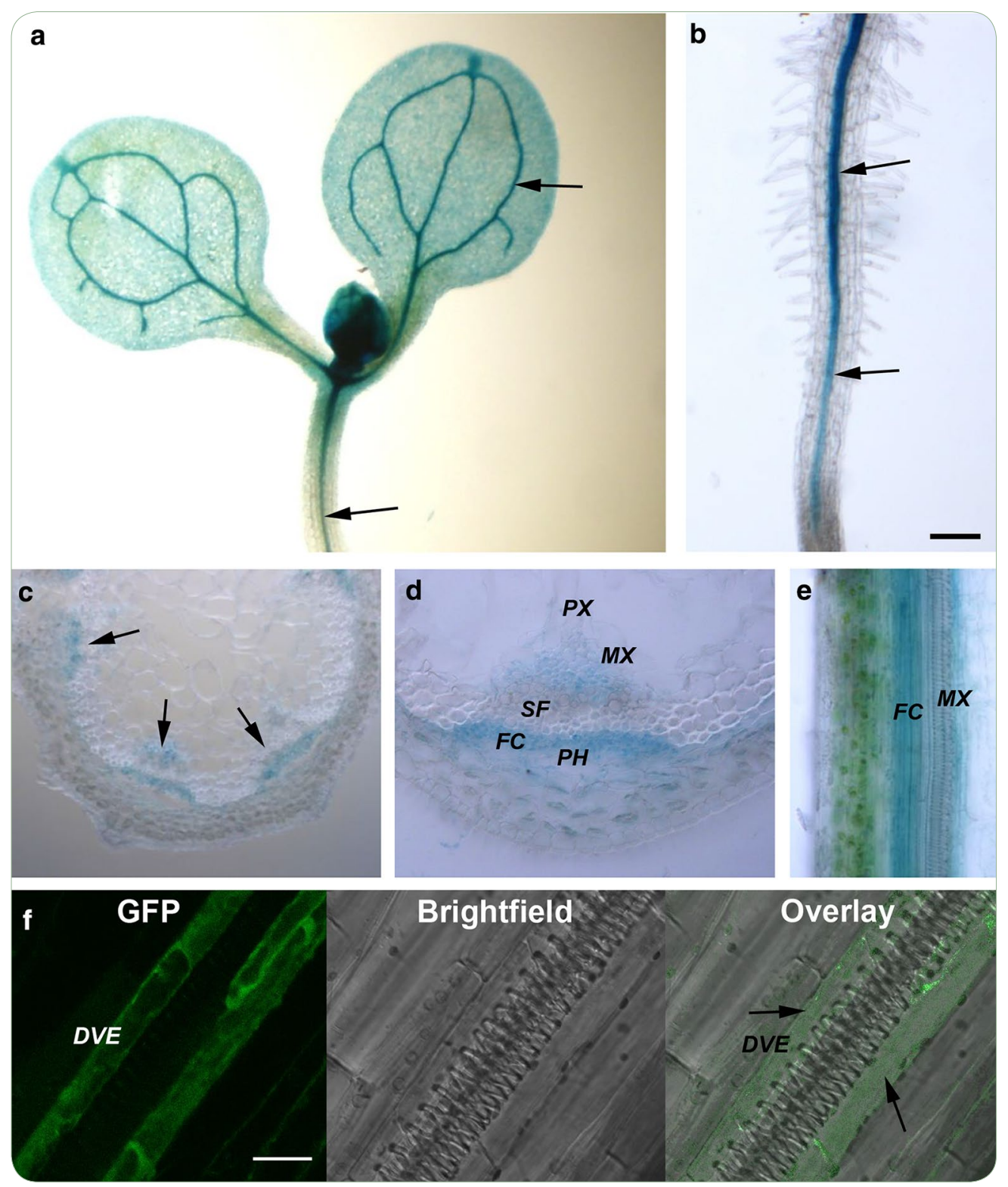

Loss of function of folylpolyglutamate synthetase 1 reduces lignin content and improves cell wall digestibility in Arabidopsis

Srivastava et al. 


\title{
Loss of function of folylpolyglutamate synthetase 1 reduces lignin content and improves cell wall digestibility in Arabidopsis
}

Avinash C. Srivastava 1,2, Fang Chen ${ }^{2,6}$, Tui Ray', Sivakumar Pattathil ${ }^{2,3,4}$, Maria J. Peña2,3, Utku Avci ${ }^{2,3,4}$, Hongjia Li ${ }^{2,5}$, David V. Huhman ${ }^{1}$, Jason Backe2,3, Breeanna Urbanowicz ${ }^{2,3}$, Jeffrey S. Miller ${ }^{3}$, Mohamed Bedair $^{1}$, Charles E. Wyman ${ }^{2,5}$, Lloyd W. Sumner ${ }^{1}$, William S. York ${ }^{2,3,4}$, Michael G. Hahn ${ }^{2,3,4}$, Richard A. Dixon ${ }^{2,6}$, Elison B. Blancaflor ${ }^{1,2}$ and Yuhong Tang ${ }^{1,2^{*}}$

\begin{abstract}
Background: One-carbon (C1) metabolism is important for synthesizing a range of biologically important compounds that are essential for life. In plants, the C1 pathway is crucial for the synthesis of a large number of secondary metabolites, including lignin. Tetrahydrofolate and its derivatives, collectively referred to as folates, are crucial co-factors for $\mathrm{C} 1$ metabolic pathway enzymes. Given the link between the $\mathrm{C} 1$ and phenylpropanoid pathways, we evaluated whether folylpolyglutamate synthetase (FPGS), an enzyme that catalyzes the addition of a glutamate tail to folates to form folylpolyglutamates, can be a viable target for reducing cell wall recalcitrance in plants.

Results: Consistent with its role in lignocellulosic formation, FPGS1 was preferentially expressed in vascular tissues. Total lignin was low in fpgs 1 plants leading to higher saccharification efficiency of the mutant. The decrease in total lignin in fpgs 1 was mainly due to lower guaiacyl (G) lignin levels. Glycome profiling revealed subtle alterations in the cell walls of fpgs1. Further analyses of hemicellulosic polysaccharides by NMR showed that the degree of methylation of 4-O-methyl glucuronoxylan was reduced in the fpgs 1 mutant. Microarray analysis and real-time qRT-PCR revealed that transcripts of a number of genes in the $\mathrm{C} 1$ and lignin pathways had altered expression in fpgs 1 mutants. Consistent with the transcript changes of C1-related genes, a significant reduction in S-adenosyl-L-methionine content was detected in the fpgs 1 mutant. The modified expression of the various methyltransferases and lignin-related genes indicate possible feedback regulation of C1 pathway-mediated lignin biosynthesis.
\end{abstract}

Conclusions: Our observations provide genetic and biochemical support for the importance of folylpolyglutamates in the lignocellulosic pathway and reinforces previous observations that targeting a single FPGS isoform for downregulation leads to reduced lignin in plants. Because fpgs 1 mutants had no dramatic defects in above ground biomass, selective down-regulation of individual components of $\mathrm{C} 1$ metabolism is an approach that should be explored further for the improvement of lignocellulosic feedstocks.

Keywords: Arabidopsis, Bioenergy, C1 metabolism, Cell-wall recalcitrance, FPGS1, Lignin, Folylpolyglutamate synthetase

\footnotetext{
*Correspondence: ytang@noble.org

2 BioEnergy Science Center, United States Department of Energy, Oak

Ridge, TN 37831, USA

Full list of author information is available at the end of the article
} 


\section{Background}

One-carbon (C1) metabolism is important for synthesizing a range of biologically important compounds such as purines and amino acids [1]. C1 enzymes use tetrahydrofolate and its derivatives, collectively referred to as folates, as cofactors for many of the biochemical reactions that they catalyze [2]. Methionine is an important product of the $\mathrm{C} 1$ metabolic pathway because it is the direct precursor of $S$-adenosyl L-methionine (AdoMet), the universal methyl-group donor, which is crucial for the synthesis of a large number of secondary metabolites [3], such as lignin, betaines, phytohormones [4], and hemicellulosic 4-O-methyl glucuronoxylan (GX) [5].

Lignin is a complex, polymeric phenylpropanoidderived compound, which confers mechanical strength to the cell wall by cross-linking different polysaccharides, especially in fibers and tracheary elements [6]. The presence of lignin in secondary cell walls creates a hydrophobic environment in the vascular tissue for water conductance [7]. In plants, there are three major types of lignin monomers, namely p-coumaryl, coniferyl, and sinapyl alcohol [8]. Lignin biosynthesis is one of the most thoroughly investigated metabolic pathways in plants, but details on intermediate steps remain contentious and we have just started learning about the metabolic complexes that regulate flux through the phenylpropanoid pathway [9-12]. Recently, interaction of lignin with other wall matrix components has become a focus of cell wall research [13].

Lignin accounts for about $30 \%$ of organic carbon on Earth [14] and is one of the major secondary compounds that utilizes a significant amount of AdoMet, the universal C1 pathway methyl donor. This has been shown in birch wood when the combined demands of several primary and secondary metabolites have been compared [3]. However, there is very little molecular evidence to show that these two pathways are directly linked. Although early radio-tracer experiments demonstrated that the methyl carbon of methionine, a precursor of AdoMet, was found in the $O$-methyl group of lignin [15], most of the studies to date have only provided indirect evidence linking $\mathrm{C} 1$ metabolism to lignin biosynthesis. For example, enriched transcripts of $\mathrm{C} 1$ metabolism genes in the lignin-rich vascular-tissues of various plant species were used to argue for a tight link between lignin biosynthesis and $\mathrm{C} 1$ reactions [16-18]. Only recently, mutant studies in model and crop plants are beginning to shed more light on the relationship between lignin biosynthesis and $\mathrm{C} 1$ metabolism. For instance, it was shown that a single-point mutation in the S-adenosylmethionine synthetase3 (SAMS3) gene resulted in decreased AdoMet and lignin content in Arabidopsis [19]. More recent research in maize has demonstrated that a mutation in the methylenetetrahydrofolate reductase (MTHFR) gene resulted in reduced lignin [20].

The supply of methyl units is also important for the synthesis of other major components of secondary walls such as the hemicellulose 4-O-methyl glucuronoxylan (GX) [21]. A study conducted on Arabidopsis glucuronoxylan-specific methyltransferase (AtGXMT1- an enzyme that catalyzes 4-O-methylation of the glucuronic acid substituents) showed that AdoMet is the donor of methyl units to AtGXMT1 [5]. Therefore, C1 metabolism is vital for maintaining the proper synthesis of various polymers that are important in modulating the structure and physical properties of the cell wall.

In plants, the synthesis of folates involves three cellular compartments, the cytosol, mitochondria, and plastids [22]. Polyglutamylation of folates is essential for the cellular retention of this family of compounds and results in more efficient reactions for many folate-dependent enzymes [23, 24]. Most cellular folates carry a short polygamma-glutamate tail. Research has shown that removing these tails can reduce the total folate content up to $40 \%$ in Arabidopsis [25] and cause major metabolic shifts and phenotypic changes in plants [26]. Folate polyglutamylation is carried out by the enzyme folylpolyglutamate synthetase (FPGS). Initial gene cloning, functional characterization, and cellular localization of the three isoforms of FPGS [FPGS1 (plastid), FPGS2 (mitochondria), and FPGS3 (cytosol)] in Arabidopsis were described by Ravanel et al. [27]. Recently, the roles of FPGS genes in Arabidopsis have been explored through mutant analysis $[24,26,28-31]$. In addition to its impacts on early seedling development and root growth [24, 26, 30, 31], mutation of FPGS1 caused changes in DNA methylation and the histone H3K9 dimethylation status of the Arabidopsis genome [29]. There is also a recent study showing that the maize brown midrib $4(\mathrm{bm} 4)$ mutant, which is disrupted in a gene encoding a functional FPGS, has reduced lignin. The lower lignin content in the $b m 4$ mutant further reinforces the importance of $\mathrm{C} 1$ pathway in lignin biosynthesis [32].

Previously, we showed that fpgs1 mutants in Arabidopsis led to reduced levels of methionine and other $\mathrm{C} 1$ metabolic intermediates in young seedlings [26]. As a result, primary roots of the seedlings failed to develop properly. Despite the early root developmental defects, fpgs 1 mutants had above-ground growth comparable to wild-type plants [26]. Although there are recent reports that folate mutants in maize have reduced lignin [20,32], it is not clear whether lower lignin resulting from altered folate metabolism leads to a corresponding reduction in cell-wall recalcitrance. Here we show that loss of FPGS1 function in Arabidopsis leads to lower lignin and reduced cell-wall recalcitrance. The reduced lignin observed in 
fpgs1 mutants might not only be due to reduced flux of methyl units to lignin precursors, but is also a consequence of changes in the expression of genes associated with lignin biosynthesis and cell wall remodeling. These changes, in turn, result in plants with enhanced digestibility and sugar release efficiency, which are important requirements for efficient biofuel processing.

\section{Results}

FPGS1 is preferentially expressed in vascular tissues, consistent with its role in lignin biosynthesis

Lignification in plants occurs predominantly in the vascular tissues where secondary cell walls are formed. It has been shown previously that several $\mathrm{C} 1$ pathway genes that supply methyl units for lignin biosynthesis were enriched in the vascular tissues [17]. Consistent with previous reports, we found that the FPGS1 promoter fused to $\beta$-glucuronidase (GUS) (pFPGS1::GUS) was predominantly expressed in the vascular tissues of cotyledons, hypocotyls, roots of seedlings and inflorescence stems (Fig. 1a-e). Based on both cross- and longitudinal sections of the transgenic plant inflorescence stems, GUS staining was mainly concentrated at the fascicular cambium region and the transition tissues from protoxylem to metaxylem (Fig. 1c-e).

The FPGS1 expression pattern was further examined using green fluorescent protein (GFP). The entire sequence of FPGS1 consisting of the 7-kb genomic DNA fragment was fused to GFP and transformed into the fpgs1 mutant. The transgenic lines carrying FPGS1 promoter::FPGS1-GFP (pFPGS1::FPGS1-GFP) construct revealed that FPGS1 expression was most distinct in the cytosol of developing vessel elements adjacent to the metaxylem (Fig. 1f). We previously showed that pFPGS1::FPGS1-GFP is localized in both chloroplasts and the cytosol when transiently expressed in tobacco leaf epidermal cells [33]. This observation is consistent with earlier reports that the Arabidopsis FPGS1 is located in plastids and the cytosol [30]. The pFPGS1::FPGS1-GFP was shown to complement the seedling root architectural defects of the fpgs 1 mutant; however, it localized mostly to the cytosol in roots [30] similar to observations made here in developing vessel elements. The observed FPGS1 expression in the vascular tissues from GUS and GFPreporter constructs was further supported by our earlier published in situ hybridization results [26] and publicly available microarray data sets [34] (Additional file 1: Fig. S1).

Unlike FGPS1, expression of the other two Arabidopsis FPGS isoforms (i.e. FPGS2 and FPGS3) is not particularly high in stems compared to other tissues. FPGS2 is most highly expressed in leaves, whereas FPGS3 is most predominantly expressed in rosette leaves and floral organs as suggested by publicly available microarray data sets [34]. Publicly available microarray data sets also show that FPGS2 and FPGS3 have lower expression in vascular tissues compared to FPGS1 [34].

\section{Lignin content is reduced in fpgs 1 mutants}

Metabolic profiling revealed that levels of many phenolic acids (cinnamic, p-coumaric, ferulic, and sinapic acids), as well as phenylalanine and coniferyl alcohol, were significantly reduced in 7-day-old fpgs1-1 mutants compared to wild type ([26]; Additional file 2: Fig. S2). These data prompted us to examine lignin content and composition in the fpgs 1-1 mutants. To complement our lignin histochemical assays, lignin levels were quantified using the acetyl bromide ( $\mathrm{AcBr}$ ) method. We found a $17 \%$ reduction in total lignin content in 35-day-old fpgs 1 plants compared to controls (Fig. 2). Lignin content of mutants of the other two isoforms of the three-membered Arabidopsis FPGS family (fpgs 2 and fpgs3) did not differ from that of the wild type (Fig. 2a). Two other fpgs 1 mutant alleles, namely fpgs 1-2 and fpgs 1-3, also exhibited a significant reduction in total lignin (Fig. 2b). Additional evidence that a mutation in FPGS1 was the cause of the lower lignin levels in mutant plants was obtained by introducing the $p F P G S 1:: F P G S 1-G F P$ construct into the fpgs1-1 background. The fpgs 1-1 plants expressing the pFPGS1::FPGS1-GFP construct restored lignin to wildtype levels (Fig. 2a). The thioacidolysis method was used to determine lignin composition in the fpgs 1 mutants and wild type. Compared with the wild-type plants, a 22.5 , 17.7 , and $17.8 \%$ reduction in G-lignin monomer was observed in the three fpgs1 mutant alleles accordingly. No significant changes in S- or H-lignin monomers were observed in all fpgs 1 mutant alleles compared to the wildtype plants (Fig. 2b).

\section{Transcript profiling of $f p g s 1$ inflorescence stems reveals down-regulation of genes in the phenylpropanoid, methylation, and $\mathrm{C} 1$ pathways}

To determine if changes in gene expression due to the FPGS1 mutation could partly explain the reduced lignin phenotype of the fpgs 1 mutant, we conducted microarray analysis of 35-day-old inflorescence stem tissues using the ATH1 Affymetrix chip. Using a Bonferroni-corrected $P$ value of $2.19202 \mathrm{E}-06$ and a ratio of two as the cutoffs, there were 409 genes differentially expressed between the fpgs1-1 mutants and wild-type plants. In the mutant, 182 genes had higher expression and 227 had lower expression (Additional file 3: Table S1/Sheet 2). The most up-regulated gene in the mutant was a member of the $R 2 R 3-M Y B$ transcription factor gene family. Although the specific function of this $R 2 R 3$ gene is not known, several members of this family of transcription factors have 

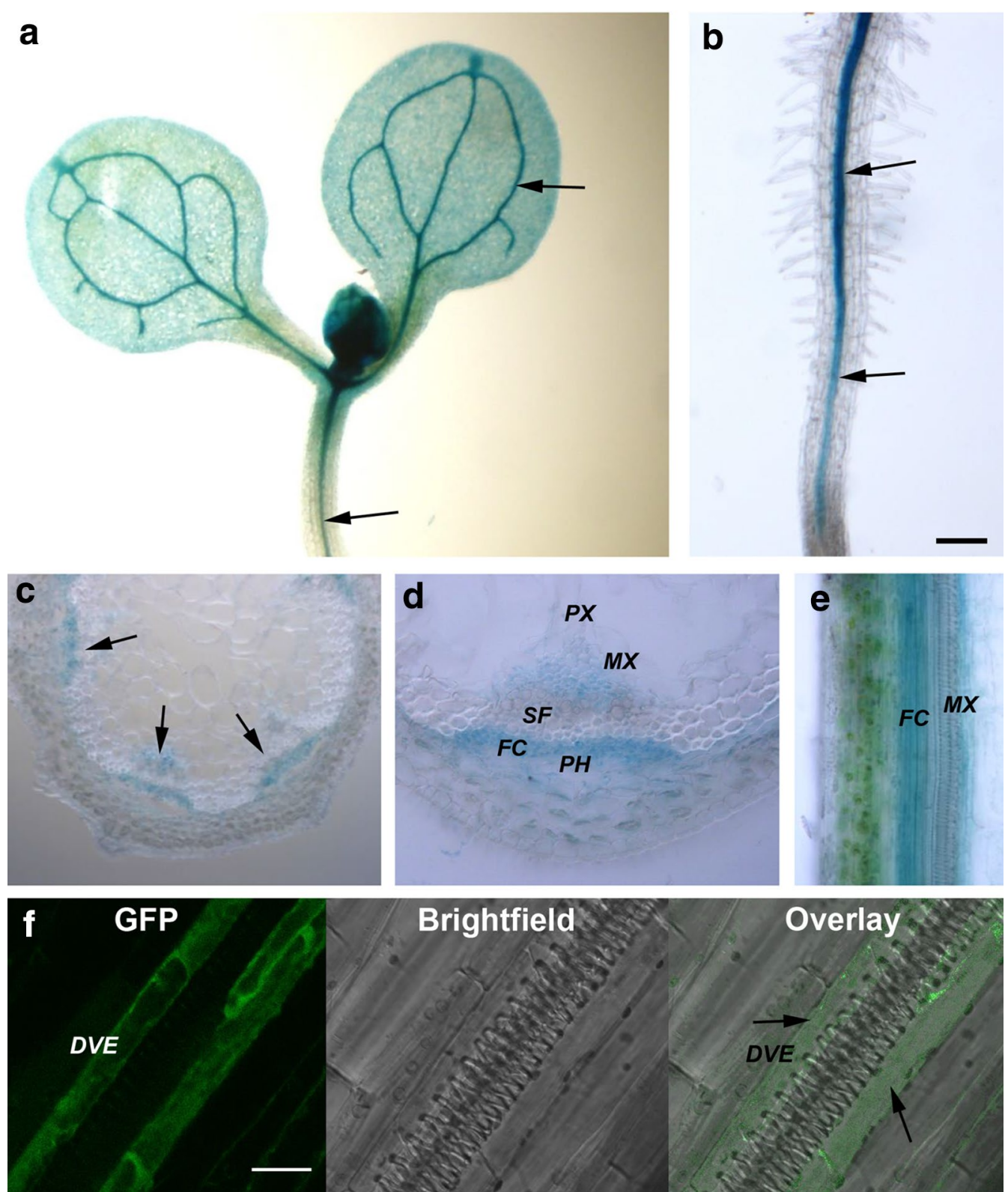

Fig. 1 Expression pattern of AtFPGS1. a, b Plants transformed with pFPGS1::GUS constructs showing FPGS1 expression in the vascular bundles of cotyledons and hypocotyls (a) and roots (b) of young seedlings. c, d Cross sections of the stained transgenic inflorescence stems showing FPGS1 expression in the fascicular cambium and xylem tissue between protoxylem and metaxylem. e Longitudinal section of pFPGS1::GUS transgenic plants showing FPGS1 expression in the fascicular cambium and xylem region adjacent to metaxylem. $\mathbf{f}$ Longitudinal inflorescence stem-sections $(100 \mu \mathrm{m})$ of plants expressing PFPGS1::FPGS1-GFP were examined for GFP fluorescence. GFP signals were mainly detected in the developing vessel elements adjacent to the differentiated metaxylem. Superimposed image of GFP over a light microscopy image shows the locations of metaxylem and the GFP expressing cells. Arrows highlight the vascular tissue where FPGS1 expression signal is detected in the cytosol. Phloem (PH), protoxylem (PX), metaxylem (MX), developing vessel element (DVE), sclerenchyma fiber (SF), and fascicular cambium (FC). Scale bar $20 \mu \mathrm{m}$

been shown to regulate lignin biosynthesis $[9,10]$. Two genes encoding $O$-methyltransferases and two encoding glycine-rich family proteins were among the top 10 most down-regulated genes in the mutant. At a ratio cutoff of two, 11 putative phenylpropanoid pathway-related genes were among the differentially expressed genes, and the majority of these were down-regulated, including one putative caffeoyl-CoA 3-O-methyltransferase (CCoAOMT/At1g67980) (Additional file 3: Table S1/ Sheet 3). 

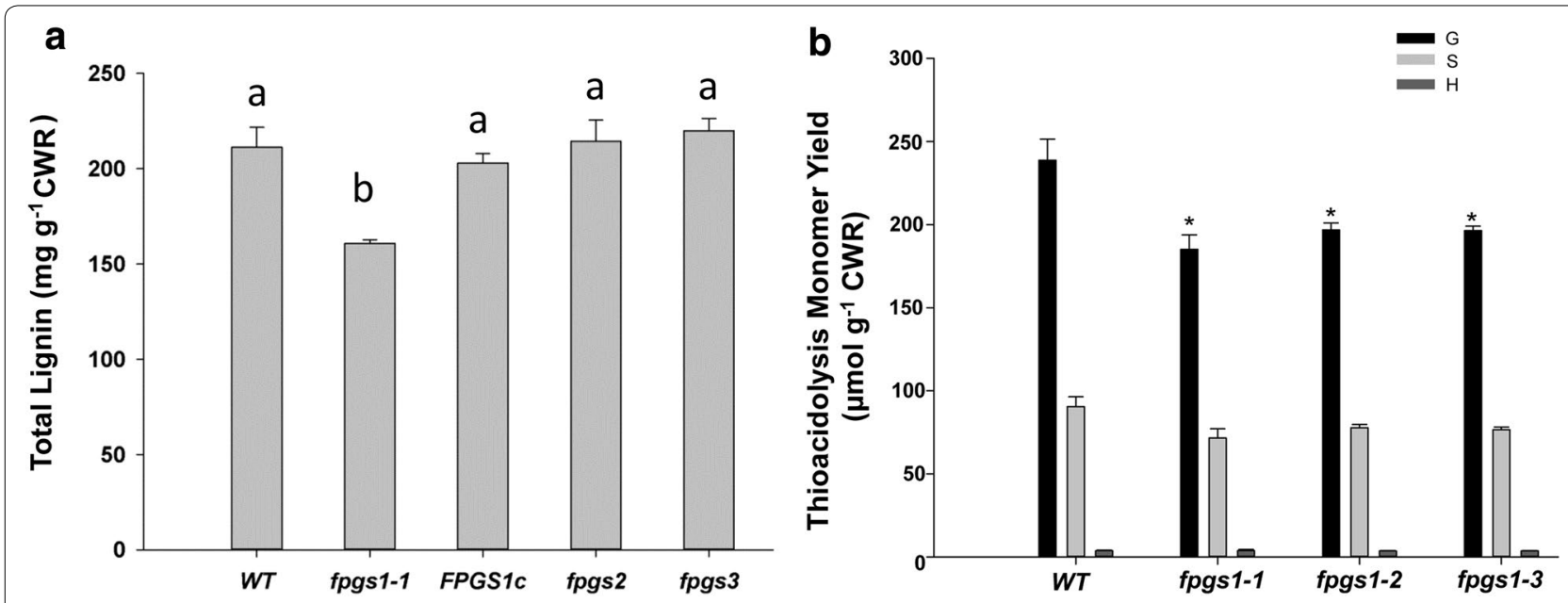

Fig. 2 Lignin content and composition analysis in the 35-day-old stems of wild type, fpgs 1 and related lines. a Alterations in total lignin content measured by the acetyl bromide (AcBr) method in fpgs 1 lines, knockout mutants of the other two isoforms of fpgs (fpgs2 and fpgs3), and complemented FPGS1c. Results showed that total lignin was significantly less in the fpgs 1 mutants and returned to the WT level in FPGS1c. Each data point was collected from five biological replicates. Each biological replicate had mature inflorescence stems of 20 individual plants (pooled). Means with different letters are statistically significant (Tukey's test, $P<0.05$ ). b Levels of $\mathrm{S}, \mathrm{G}$ and $\mathrm{H}$ units were measured by the thioacidolysis method in all three mutant alleles of fpgs 1 (fpgs 1-1, fpgs 1-2, fpgs 1-3) and compared with the wild-type plants. For each biological replicate, mature inflorescence stems of 20 individual plants were pooled and assayed for lignin monomers. The data represent the average value of five biological repeats for the mutants and wild type (WT) ( \pm SE). *Statistically significant difference; $t$ test $(P<0.05)$

A total of 16,484 probe sets were detected in the stem tissues based on the "Presence" call in at least four out of the six stem samples or in all three replicates in either wild-type or the fpgs 1 mutant based on the dCHIP program (http://www.hsph.harvard.edu/cli/complab/ dchip/). Among them, 135 probe sets were known or homologous to known lignin pathway enzymes, based on the strategy of Costa et al. [35] (see http://cahnrscms.wsu.edu/ibc/research/lewis/nsf/Pages/Genes.aspx) (Additional file 3: Table S1/Sheet 2/sheet3). Using a ratio cutoff of 1.5, the expression of 25 probe sets annotated as known or putative lignin pathway genes (18.5\%, 2.53 times enrichment over the background) were affected in the fpgs 1 mutant. Similarly, 244 probe sets on the chip annotated as methyltransferases were detected in the stem tissue. Among the genes annotated as methyltransferases, the expression of 25 probe sets $(10.3 \%, 1.42$ times enrichment over the background) was affected in the fpgs1 mutant with most of them down-regulated (Additional file 3: Table S1/Sheet 4).

Among the genes directly involved in the $\mathrm{C} 1$ metabolic pathway, expression of homocysteine S-methyltransferase3 (HMT3), which encodes an enzyme that converts homocysteine to methionine in the S-methylmethionine (SMM) cycle, was six times higher in the mutant. Similarly, the expression of S-adenosylmethionine synthetase 3 and 4 (SAMS3, SAMS4) was also up-regulated. On the other hand, expression of SAMS1, SAMS2, and several AdoMet-dependent methyl transferases was significantly down-regulated (Table 1; Additional file 3: Table S1). We also observed that significant numbers of genes involved in the sulfur assimilation pathway were affected in the mutant. Among 28 genes involved in sulfur metabolism, 13 were affected in the fpgs 1 mutant, with the majority of them up-regulated (Additional file 3: Table S1/Sheet 5).

We validated our microarray data by quantitative real-time qRT-PCR in 35-day-old stem tissues of fpgs11 and wild-type plants, focusing on the genes potentially involved in lignin biosynthesis and $\mathrm{C} 1$ pathways. Twenty-two genes, including one putative CCoAOMT (AT1G67980), one $O$-methyltransferase family protein (AT1G33030), three SAM synthetases (AT3G17390, AT1G02500, AT4G01850), several AdoMet-dependent methyltransferases superfamily protein (AT3G54150, AT1G15125, AT1G69526, AT4G22530, AT1G66690), and Laccase 4 (AT2G38080) were tested and validated (Table 1).

\section{Levels of the methyl group donor AdoMet and the degree of methylation of GX were reduced in fpgs 1}

AdoMet is the major methyl-group donor for numerous transmethylation reactions [36]. Methionine is the immediate precursor of AdoMet and we have shown previously that methionine levels are reduced in fpgs 1 mutant seedlings [26]. To determine if the mutation in FPGS1 also affects AdoMet content, we quantified AdoMet by HPLC based on the method described by Castro et al. ([37]; Additional file 4: Fig. S3). Extracts from fpgs1-1 mutant 
Table 1 Relative expression levels of selected genes in wild-type and fpgs 1-1 plants estimated by two methods

\begin{tabular}{|c|c|c|c|c|c|}
\hline \multirow[t]{3}{*}{ Gene ID } & \multirow[t]{3}{*}{ Gene description } & \multicolumn{3}{|c|}{ Real time qRT-PCR } & \multirow{3}{*}{$\begin{array}{l}\text { Microarray } \\
\text { Ratio } \\
\text { (fpgs 1/WT) }\end{array}$} \\
\hline & & \multicolumn{2}{|c|}{ Relative to internal standard } & \multirow{2}{*}{$\begin{array}{l}\text { Ratio } \\
\text { (fpgs 1/WT) }\end{array}$} & \\
\hline & & fpgs 1-1 & WT & & \\
\hline AT1G67980 & $\begin{array}{l}\text { S-adenosyl-L-methionine: trans-caffeoyl Coenzyme } \\
\text { A 3-O-methyltransferase }\end{array}$ & 0.164 & 0.936 & $0.18^{*}$ & $0.281^{* *}$ \\
\hline AT1G21100 & Indole glucosinolate O-methyltransferase 1 & 0.665 & 2.411 & $0.28^{*}$ & $0.193^{* *}$ \\
\hline AT3G54150 & SAM-dependent methyltransferases superfamily protein & 0.184 & 0.634 & $0.29^{*}$ & $0.270^{* *}$ \\
\hline AT1G15125 & SAM-dependent methyltransferases superfamily protein & 2.591 & 8.325 & $0.31^{*}$ & $0.380^{* *}$ \\
\hline AT1G69526 & SAM-dependent methyltransferases superfamily protein & 0.02 & 0.048 & $0.41^{*}$ & $0.500^{* *}$ \\
\hline AT1G33030 & Caffeic acid 3-O-methyltransferase family protein & 0.126 & 0.288 & $0.44^{*}$ & $0.449^{* *}$ \\
\hline AT4G22530 & SAM-dependent methyltransferases superfamily protein & 0.08 & 0.174 & $0.46^{*}$ & $0.491^{* *}$ \\
\hline AT2G38080 & Laccase 4 & 23.317 & 33.473 & $0.70^{*}$ & 0.97 \\
\hline AT1G02500 & S-Adenosylmethionine synthetase 1 (SAMS1) & 180.713 & 255.93 & $0.71^{*}$ & 0.96 \\
\hline AT1G66690 & SAM-dependent methyltransferases superfamily protein & 0.004 & 0.005 & $0.71^{*}$ & $0.65^{* *}$ \\
\hline AT4G01850 & S-Adenosylmethionine synthetase 2 (SAMS2) & 10.468 & 14.607 & $0.72^{*}$ & $0.85^{* *}$ \\
\hline AT1G15950 & Cinnamoyl CoA reductase 1 & 23.261 & 31.304 & $0.74^{*}$ & 1.12 \\
\hline AT5G04230 & L-Phenylalanine ammonia-lyase 3 & 0.275 & 0.354 & $0.78^{*}$ & $0.67^{* *}$ \\
\hline AT1G72680 & Cinnamyl alcohol dehydrogenase 1 & 0.558 & 0.693 & $0.80^{*}$ & 0.89 \\
\hline AT2G36880 & Methionine sdenosyltransferase 3 (SAMS4) & 9.275 & 6.237 & $1.49^{*}$ & $1.35^{* *}$ \\
\hline AT3G17390 & S-Adenosylmethionine synthetase 3 (SAMS3) & 10.637 & 6.958 & $1.53^{*}$ & $1.32^{* *}$ \\
\hline AT3G22740 & Homocysteine S-methyltransferase 3 (HMT3) & 0.303 & 0.035 & $8.70^{*}$ & $6.158^{* *}$ \\
\hline
\end{tabular}

* Student $t$ test $P<0.05$

** Associative analysis $P<2.20 \mathrm{E}-06$ (Bonferroni corrected $P$ value cutoff)

stems had about $50 \%$ less AdoMet content than extracts from wild-type stems (Fig. 3a).

GX and lignin are the major polymers in the secondary cell wall that contain methyl groups. To determine if the reduced AdoMet content found in the fpgs1-1 stems alters xylan methyletherification, we analyzed the structure of GX isolated from 35-day-old inflorescence stems of wild-type and fpgs 1-1 mutant by ${ }^{1} \mathrm{H}-\mathrm{NMR}$ spectroscopy, as described previously [5]. The NMR analyses showed that the degree of GlcA $O$-methylation of GX in fpgs 1-1 was $10 \%$ lower than wild type (Fig. 3b, c). Other GX structural features, including the amount of branching and degree of polymerization were identical.

\section{Glycome profiling reveals subtle alterations in the cell walls of fpgs 1 inflorescence stems}

Changes in lignin composition typically lead to corresponding modifications in other components of the cell wall [38-42]. To determine if there were any alterations in the overall extractability of non-cellulosic glycan epitopes in the fpgs 1-1 mutant, glycome profiling of the cell wall material (alcohol insoluble residues; AIR) isolated from 35-day-old inflorescence stems of wild-type and fpgs1-1 mutants was conducted (Fig. 4a). The glycome profiles of the fpgs 1-1 mutants were mostly similar to those of wild-type lines. However, a subtle reduction in the overall abundance of xyloglucan (non-fucosylated and fucosylated) and xylan epitopes was observed in the $1 \mathrm{M} \mathrm{KOH}$ and chlorite extracts of fpgs 1-1 mutant walls (see white dotted blocks in Fig. 4a). Overall, when the total amounts of carbohydrate released during the various extractions were quantitated, it was noted that mild extractions released higher amounts of carbohydrate from cell walls of fpgs1-1 inflorescence stems (significantly higher in oxalate and marginally higher in carbonate extracts) indicating that the extractability of cell walls from fpgs1-1 was slightly higher than from wild type. Differences between fpgs1-1 and wild-type wall extracts were also noted with respect to the binding of individual antibodies (see white arrows in Fig. 4a). Based on replicated data of glycome profiling, several mAbs that exhibited significant (student $t$ test, $P<0.05$ ) altered binding responses to the extracts from fpgs 1-1 mutants' cell walls in comparison to wild type indicated changes in the abundances of their epitope structures in the extracts from mutants. For instance, in mutant cell wall extracts, enhanced binding responses were noted for some mAbs, including CCRC-M96 (belonging to the non-fucosylated xyloglucan-5 clade) in oxalate, chlorite, and PC $4 \mathrm{M} \mathrm{KOH}$ extracts; CCRC-M107 (belonging to the arabinogalactan-2 clade) in oxalate and carbonate extracts; and CCRC-M131 (belonging to the homogalacturonan 


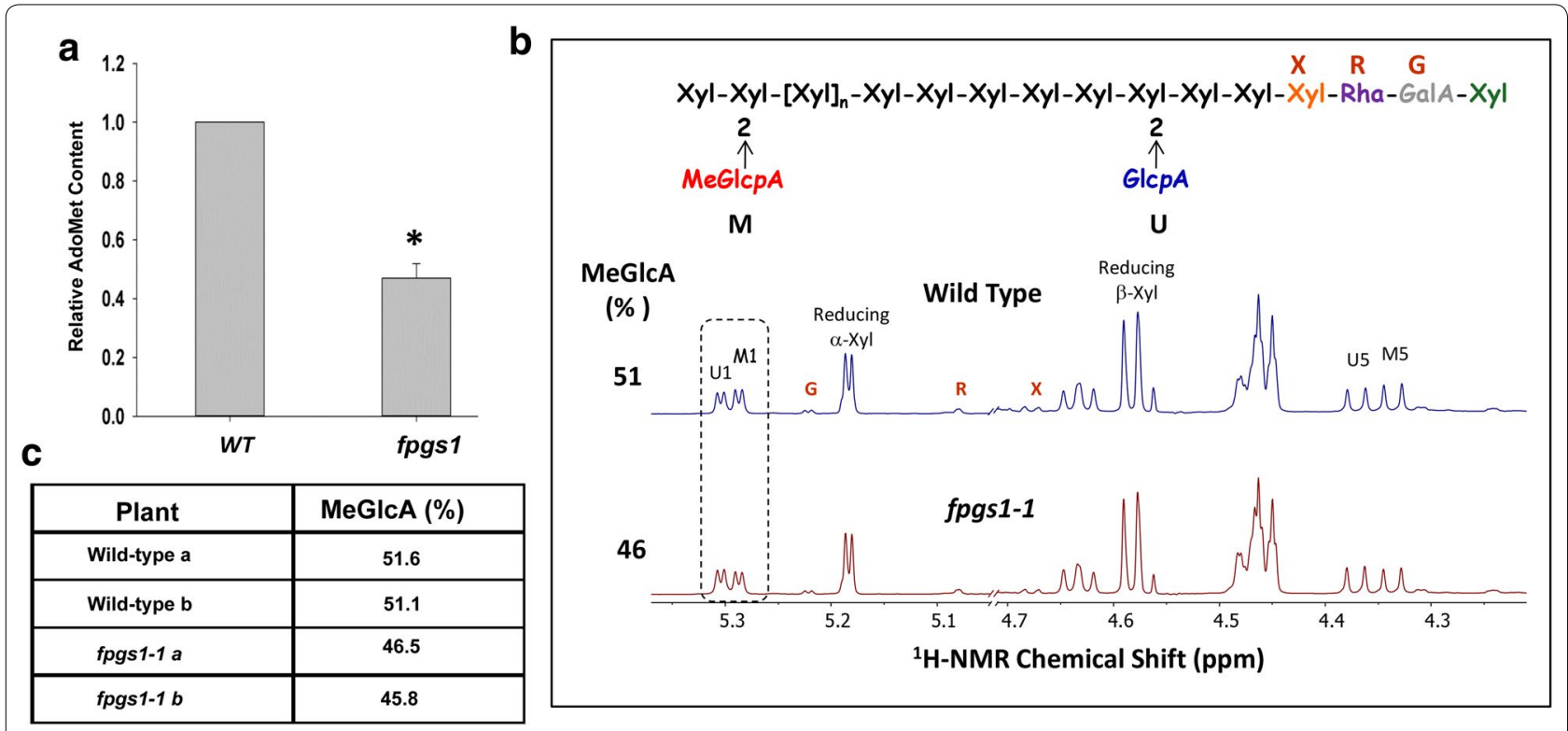

Fig. 3 Relative S-adenosyl L-methionine (AdoMet) content and the degree of GX methylation in fpgs 1 and wild-type plants. a SAM content in wildtype (WT) and fpgs 1 stem tissue samples analyzed according to the method of Castro et al. [37]; a twofold reduction in AdoMet was observed in the fpgs 1-1 compared to WT plants. Five biological replicates were used during the measurement. b Determination of the degree of GlcA O-methylation of 4-O-methyl glucuronoxylan (GX) isolated from fpgs 1-1 and wild-type stem cell walls. Xylo-oligosaccharides were generated by endoxylanase treatment of the $1 \mathrm{~N} \mathrm{KOH}$-soluble $\mathrm{GXs}$ and analyzed using 600-MHz $1 \mathrm{H}$ NMR spectroscopy. The $\mathrm{H}-1$ and $\mathrm{H}-5$ resonances of a-D-GIcpA residues are labeled U1 and U5, respectively. The M1 and M5 labels correspond to $\mathrm{H}-1$ and $\mathrm{H}-5$ of 4-O-methyl a-D-GlcpA. Resonances assigned as $\mathrm{H}$-1 of a-DGalpA, a-L-Rhap, and $\beta-D-X y l p$ linked to Rha residues are labeled G, R and X, respectively. The degree of GlcA methylation was determined by integration of U1 and M1 in the 1-D spectra (dotted box). c The NMR analyses of GX oligosaccharides were generated by two independent endoxylanase treatments showed a $10 \%$ reduction of the degree of GlcA O-methylation of fpgs 1-1 GX compared with wild-type GX

backbone-1 clade) in carbonate extracts. Some mAbs exhibited reduced binding responses in mutant cell wall extracts, including CCRC-M90 (belonging to the nonfucosylated xyloglucan-6 clade) in $4 \mathrm{M} \mathrm{KOH}$ and PC $4 \mathrm{M}$ $\mathrm{KOH}$ extracts; CCRC-M111 (belonging to the xylan-1/ xyloglucan clade); CCRC-M24, CCRC-M25, and CCRCM134 (all belonging to the RG-I/arabinogalactan clade) in the PC $4 \mathrm{M} \mathrm{KOH}$ extract (Additional file 5: Table S3). These data, in general, suggest potential cell wall alterations in fpgs 1-1.

To determine if these minor differences in glycome profiling between wild type and fpgs 1-1 are reflected in situ, immunolabeling of cross-sections of 35-day-old inflorescence stems was conducted using monoclonal antibodies directed against a fucosylated xyloglucan epitope (CCRC-M1), a xylan epitope (CCRC-M152), an arabinogalactan side chain epitope of RG-I (CCRC-M25/ RG-I/AG) and a non-methylesterified homogalacturonan epitope (CCRC-M38). All of these mAbs labeled wildtype and fpgs 1-1 mutant stems in a similar fashion, indicating no major compositional differences in the cell wall epitopes recognized by these antibodies between wildtype and the fpgs 1 mutants (Fig. 4b). It is worth noting that CCRC-M25 showed a significant difference in the glycome profiles for the PC $4 \mathrm{M} \mathrm{KOH}$ extracts, but such differences were not obvious in the in situ imaging.

Since homogalacturonan is another major sink for methyl groups, the difference in pectin methylation was examined by looking at the glycome profiling data for JIM5 and JIM7, antibodies that distinguish pectin with different degrees of methylation $[43,44]$, neither showed significance differences between wild type and fpgs1-1. This observation was consistent with immunolocalization of stem inflorescence sections, which also did not reveal differences in labeling intensities by these two antibodies between wild type and fpgs1-1. Taken together, our results suggest that subtle changes in wall extractability (as reflected in the glycome profiles) in the mutant are not accompanied by obvious changes in wall epitope composition, including pectin methylation.

\section{Saccharification efficiency is enhanced in fpgs 1 mutants}

Mature whole plants (stem and leaves) were analyzed for sugar release. Sugar release from the cell wall residues (CWRs) without acid pretreatment was 41 and $19 \%$ more in the fpgs 1-1 and fpgs 1-3 plants, respectively, when compared to wild-type plants (Fig. 5a). Enzymatic hydrolysis of the CWR with acid pre-treatment showed 23 and $37 \%$ 
a

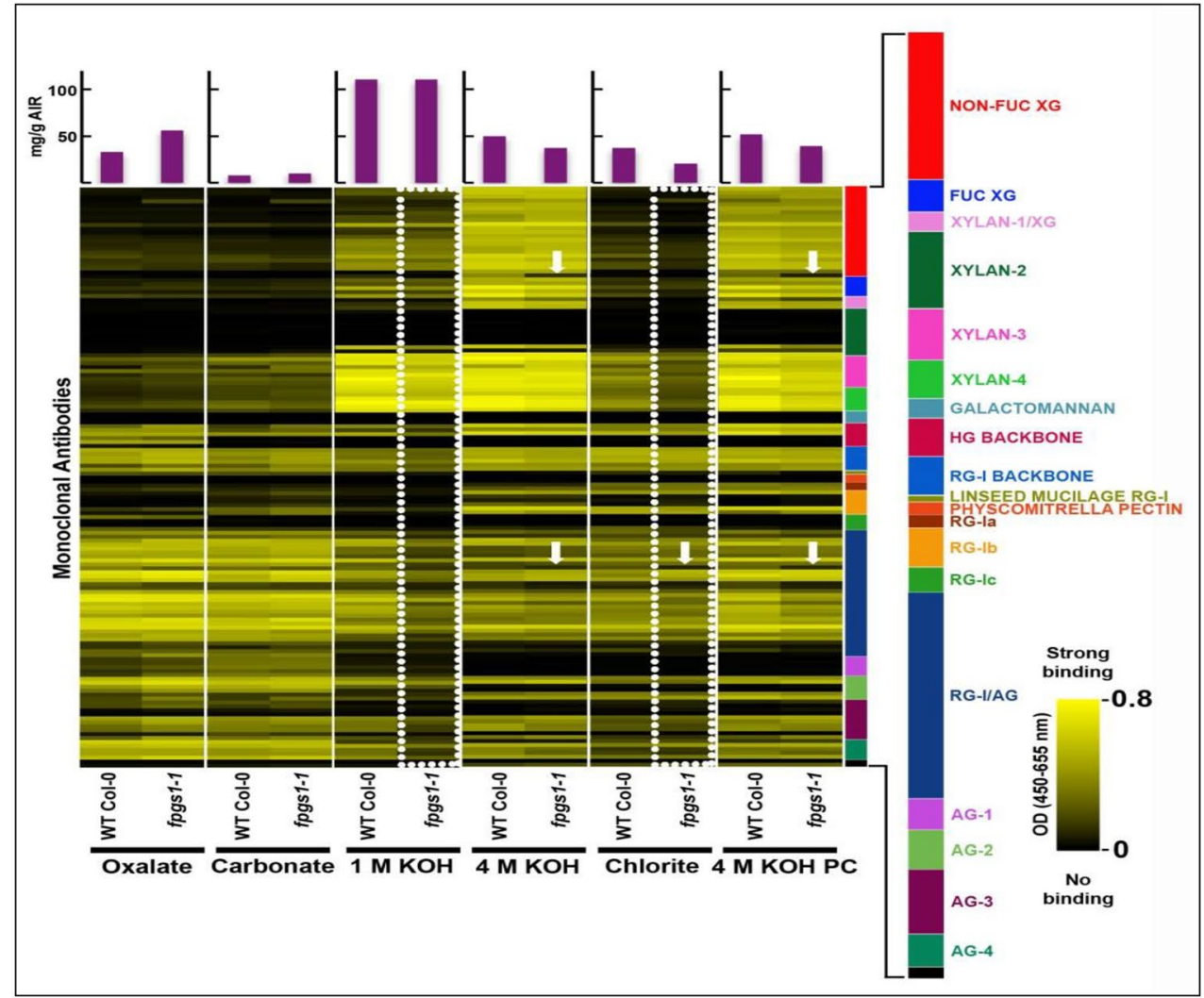

b
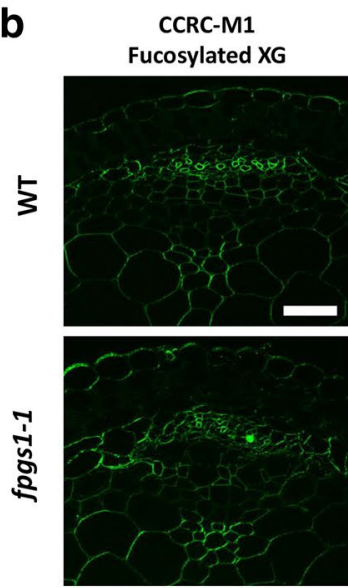

CCRC-M152

Xylan
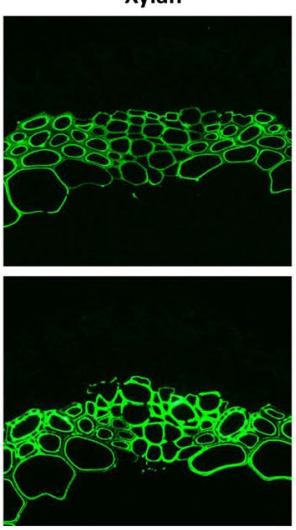

CCRC-M25

RG-I/AG
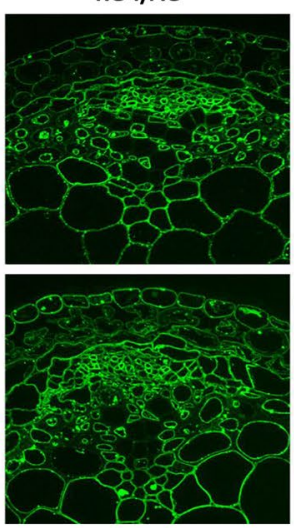

CCRC-M38

De-esterified HG
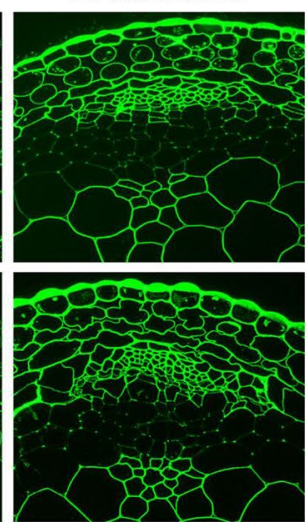

Fig. 4 Immunological analyses of stems harvested from wild-type and fpgs 1-1 plants. a Glycome profiling of sequential extracts prepared from the cell walls isolated from 35-day-old stems of fpgs $1-1$ and wild-type plants. The data are the average of three independent biological replicates. The various extraction reagents used are indicated at the bottom of the figure. The bar graphs above show amounts of carbohydrate materials released at each extraction step. Please note that these are sequential extracts (and not individual treatments) and reduced amounts released in last three extracts in mutant lines are potentially caused by the loss of excess carbohydrate materials in earlier lesser harsh extraction steps such as oxalate extraction. The panel on the right depicts the clades of monoclonal antibodies that recognize most major classes of plant cell wall glycans. The dotted boxes and arrows highlight the differences in the glycome profiles between fpgs 1-1 and wild-type plants. The yellow-black scale indicates the strength of the ELISA signal: bright yellow color depicts the strongest binding and the black color indicates no binding. b Immunofluorescence labeling with four selected antibodies representing different clades of glycans. Tissue was harvested from 35-day-old plants and fixed and sectioned as described in "Methods". (Scale bar $25 \mu \mathrm{m}$ and is applicable to all images) 


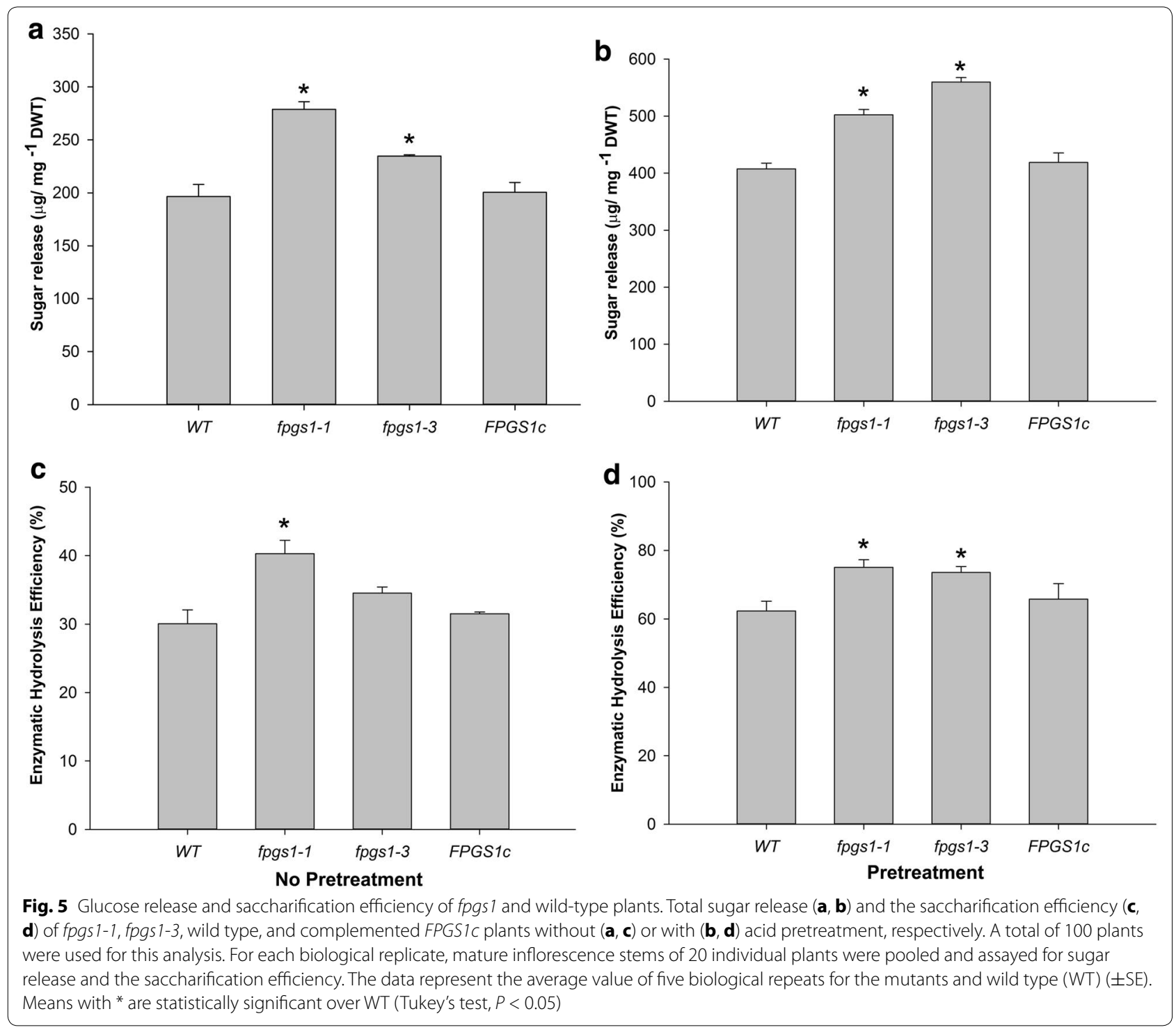

higher sugar release in the fpgs 1-1 and fpgs1-3 mutants, respectively, compared to wild-type plants (Fig. 5b). Accordingly, the saccharification efficiency of the mutant increased around 14-20\% without acid pre-treatment and around 18-34 \% with acid pre-treatment (Fig. 5c, d). It is worth pointing out that the sugar release of the pFPGS1::FPGS1-GFP complemented lines (FPGS1c) was similar to the wild type, providing evidence that the improved saccharification efficiency in the fpgs 1 mutant is indeed directly attributable to the mutation.

An independent test was performed on wild-type and fpgs 1 CWRs using more sensitive HPLC methods. Although no major structural changes in the cell wall were noticed, a significant $(5.88 \%)$ increase in the glucan composition was observed in the fpgs1-1 mutant
(Additional file 6: Fig. S4A). Glucose and xylose released from hydrothermal pretreatment and co-hydrolysis were measured and we found a 24 and $8 \%$ higher release of glucose and xylose, respectively, in the fpgs 1 mutant when samples were hydrothermally pretreated (Additional file 6: Fig. S4B), and 19 and $13 \%$ higher release of glucose and xylose, respectively, when samples were digested without any pretreatment (Additional file 6: Fig. S4C).

\section{Discussion}

Increasing cell wall digestibility has been achieved using various means $[45,46]$ but, mainly through the manipulation of genes encoding enzymes in the lignin biosynthetic pathway or those that directly modulate their expression 
[38-42]. Novel approaches are also being sought to reduce recalcitrance and methods such as partial substitution of normal monolignols with phenolic precursors or novel monolignols to increase carbohydrate accessibility, increase digestible sugar contents in the feedstock, and reduce substrate-derived fermentation inhibitors, all resulted in reduced recalcitrance $[45,46]$. Here, we report that the FPGS1 gene, a known component of $\mathrm{C} 1$ metabolism that supplies methyl units to lignin precursors and other cell wall components, can be an alternative target for reducing lignin content and cell wall recalcitrance. Although defects in growth were observed during early seedling development [26,30,31], such defects become less obvious in mature plants (Additional file 7: Fig. S5).

The FPGS1 localization in the xylem suggested a possible involvement of FPGS1 in lignin biosynthesis, as the xylem is a major site for this pathway. Other genes, such as Acaulis5 [47], SAMS3 [19], COMT, and CCOAOMT [48-52], which are directly involved in xylem development or lignification, were also expressed in the vascular tissues. In wild-type Arabidopsis stem tissues, transcript levels of FPGS1 were 27 times and 7 times more abundant than FPGS2 and FPGS3, respectively. This indicates that FPGS1 is the dominant FPGS isoform in the stem (Additional file 3: Table S1). The lower expression of FPGS2 and FPGS3 in stems and vascular tissues relative to FPGS1 may explain why their corresponding mutants did not show reduced stem lignin. However, we cannot discount the possibility that other tissues in fpgs 2 and fpgs3 mutants have reduced lignin.

In this study, we recorded approximately a fifty percent reduction of AdoMet in fpgs1-1 stem tissues, which corresponded to about a $17 \%$ reduction in lignin content. While a smaller impact on downstream product is generally expected due to concentrations, enzyme $K_{M}$ and regulation, we cannot discount the possibility that there may be alternative sources of methyl units for the lignin biosynthetic pathway. In addition to those supplied by the other functional FPGS isoforms (FPGS2 and FPGS3), other sources of methyl units could be obtained through the $S$-methylmethionine (SMM) cycle. Through the tandem action of Met $S$-methyltransferase (MMT) and Hcy $S$-methyltransferase (HMT), the SMM cycle transports SMM from source tissues to sink tissues to be converted to methionine, which further replenishes the depleted AdoMet pools [3, 53, 54]. In the fpgs 1 mutant stems, transcripts of HMT3 were up-regulated six times, indicating potential compensation of methyl units through the SMM cycle in the fpgs 1 .

The direct impact of the FPGS1 gene product on AdoMet content could also be due to the fact that within the $\mathrm{C} 1$ pathway, methionine synthases cannot use monoglutamylated folates as methyl donors [55, 56]. Due to lower AdoMet levels in fpgs1, the conversion of cinnamic acid into monolignols via $O$-methylation reactions catalyzed by CCOAOMT or COMTs (Additional file 8: Fig. S6); $[6,57,58]$ could be compromised. The reduced lignin content in fpgs1 knockout plants mostly showed reduced levels of G-lignin and is reminiscent of previous reports where down-regulation of CCOAOMT resulted in less lignin because of the reduction mainly in $\mathrm{G}$ units in different species [6, 48-52, 59-63]. In the fpgs 1 mutant, transcript levels of CCoAOMT1 (AT4G34050) or COMT1 (AT5G54160) were not affected. It is worth noting, however, that transcripts of several OMTs and one putative CCoAOMT (AT1G67980) were significantly down-regulated in the fpgs 1 stem tissues (Additional file 3: Table S1). Although, direct involvement of these OMTs in the lignin biosynthesis has not been established, it is likely that some of these genes are involved in cell wall biosynthesis. Elucidating the function of these $O M T$ genes will be the subject of future research.

Relationships among metabolic pathways have been shown in previous studies through transcriptomics analysis. For example, Loizeau et al. [64] found that antifolate methotrexate (MTX) treatment on Arabidopsis suspension cells induced significant changes in the expression of 4538 genes encoding FPGS, methionine synthases, methylene-THF reductases, $S$-adenosylmethionine synthetases, and methionine $S$-methyltransferases. Changes in the expression of these genes were associated with a significant modification in the distribution of $\mathrm{C} 1$ derivatives, resulting in the reorientation of $\mathrm{C} 1$ units towards the synthesis of critical biological compounds [64]. Recently, system-wide analysis of lignin biosynthesis pathway mutants also revealed that shikimate, phenylpropanoid, and methyl donor pathways are tightly coregulated [41].

The essence of plastidial FPGS1 is not just restricted to the phenylpropanoid pathway and $\mathrm{C} 1$ metabolism, but also for the sulfur homeostasis in plastids. In support of this notion is the observation that changes in expression of nearly 13 out of the 28 genes involved in sulfur metabolism, including up-regulation of a few sulphate transporter (SULTR) genes, occurred in the fpgs1 mutants. Changes in the expression of SULTR genes are typically indicative of sulfur starvation [65]. It is noteworthy that methionine salvage and AdoMet play essential roles in sulfur, ethylene, and polyamine biosynthetic pathways [66]. The altered expression of genes involved in sulfur metabolism in fpgs 1 was not surprising because the plastid is the major organelle for sulfur metabolism and the two sulfur-containing amino acids, Met and cysteine, are key players in the $\mathrm{C} 1$ pathway. Sulfur deprivation in plastids could reduce the AdoMet content up to tenfold [67]. Changes in sulfur metabolism in the fpgs 1 mutant were 
also reflected by the fact that a significant number of genes involved in methionine-derived glucosinolate biosynthesis were up-regulated. Sulfate assimilation and glucosinolate biosynthetic are known to be interconnected [68]. Collectively, these metabolic shifts may have both direct and indirect impacts on the synthesis of lignin and secondary cell wall components.

In stem tissues, other pathways involved in secondary cell wall formation, such as the xylan biosynthetic pathway, also require methylation reactions [5, 69]. Our microarray analysis of the fpgs 1 mutant showed that several AdoMet-dependent methyltransferases, especially $O$-methyltransferases, were down-regulated in the mutant. The $10 \%$ reduction in the GlcA $O$-methylation of GX in the fpgs 1-1 mutant further supports the involvement of FPGS1 in secondary cell wall synthesis. The subtle changes in cell wall polysaccharide composition revealed by glycome profiling also indicate that changes in the $\mathrm{C} 1$ pathway may affect cell wall structure.

Reduction of lignin content or alteration of lignin composition has been shown to be associated with increased saccharification efficiency and reduced recalcitrance in many crops. For example, down-regulation of COMT and $C A D$ increased saccharification efficiency in switchgrass by 16.5 and $23 \%$, respectively [70-72]. Furthermore, modification of various genes in the lignin biosynthesis pathway from different species has clearly demonstrated lignin down-regulation [38-42, 73-76]. Recent work in Arabidopsis using system biology approaches showed improved sugar release in most of the lignin downregulated plants [42]. The partial redundancy in FPGS function could be exploited for the generation of biofuel crops with lowered lignin content and minimal undesired effects on biomass yield. It should be noted, however, that FPGS2, which encodes the mitochondrial FPGS isoform, is required for efficient nitrogen utilization [28], and recently, hypocotyls showed reduced growth in darkgrown fpgs 1 seedlings [31]. Thus, we cannot rule out the possibility that down-regulation of FPGS1 could also lead to other plant developmental changes that are only manifested under certain environmental conditions. Nonetheless, the fact that FPGS1 impacts lignin formation without any major adverse effects on plant growth makes it a promising target for improvement of lignocellulosic feedstocks for sustainable biofuel production.

\section{Conclusion}

The present analysis of the Arabidopsis fpgs 1 mutants conclusively demonstrates that specific expression of FPGS1 in the vascular tissues contributes to the supply of methyl units for methylation reactions in the phenylpropanoid pathway. The increase in saccharification efficiency in the fpgs1 mutant without dramatic negative effects on biomass traits points to an alternative target for improvement of lignocellulosic feedstocks. Our work also demonstrates that the essence of plastidial FPGS1 is not just restricted to the lignocellulosic pathway, but also associated with the sulfur and glucosinolate pathways, which furthers our understanding of the complex regulation of plant secondary metabolism.

\section{Methods}

\section{Characterization of fpgs 1 mutants and plasmid} construction

The fpgs 1-1 (originally designated as drh2 or atdfb-1) mutant was identified through a forward genetic screen as described previously [26]. Two additional T-DNA insertion lines (SALK_015472, and SAIL_556_G08) at the FPGS1 locus (AT5G05980) acquired from ABRC (https:// abrc.osu.edu) were also used in this study and renamed as fpgs 1-2 and fpgs 1-3, respectively. Plant growth and molecular characterization of all of these mutants were as described by Srivastava et al. [26]. Most of the analyses described here were conducted on the fpgs 1-1 mutant unless otherwise indicated.

All constructs were made using Gateway ${ }^{\mathrm{TM}}$ technology (Invitrogen, Now Life Technologies). The entry clones were obtained using the pENTR-D-TOPO vector (Invitrogen) and expression vectors using the Gateway system [77]. These were propagated in the E. coli strain Top 10 (Invitrogen) and DH5 $\alpha$, respectively. The templates used to clone all genes were genomic DNA or cDNA derived from $A$. thaliana Col-0 RNA. The 2-kb promoter region (upstream of the ATG start codon of FPGS1) was amplified using Taq DNA polymerase (Invitrogen), cloned into pENTR-D-TOPO, and later fused to uidA GUS reporter gene via LR-reaction in the destination vector PMDC162 for tissue expression analysis. The constructs were transformed into Agrobacterium tumefaciens strain LBA4404. For complementation studies, a 7-kb genomic DNA fragment containing the pAtFPGS1-FPGS1 was amplified using gene-specific primers (Additional file 9: Table S2). This construct is comprised of $2 \mathrm{~kb}$ upstream promoter and $5 \mathrm{~kb}$ downstream regions of the ATG start codon. This was cloned into $p M D C 107$ binary vectors and transformed into A. tumefaciens LBA4404. The fpgs 1-1 mutant was then transformed using the floral-dip method [78]. Transgenic plants were selected on $25 \mu \mathrm{g} \mathrm{ml}^{-1}$ hygromycin plates and later propagated on soil. Around ten independent $\mathrm{T} 2$ transgenic lines were tested and analyzed for fluorescence and complementation.

\section{Lignin analysis}

Lignin content and composition were measured in the post-flowering 35-day-old stem tissues by the AcBr [79] and thioacidolysis [80] methods. At this stage, plants 
had well-developed inflorescence stems, which was optimal for lignin quantification. Because 35-day-old plants were still mostly green, this time point was chosen so we could obtain quality RNA for gene expression data that corresponded to lignin analysis. Lignin-derived monomers were identified and quantified by GC/MS using a Hewlett-Packard 5890 series II gas chromatograph with a 5971 series mass selective detector (column: HP-1, $60 \mathrm{~m} \times 0.25 \mathrm{~mm} \times 0.25 \mu \mathrm{m}$ film thickness). Mass spectra were recorded in electron impact mode $(70 \mathrm{eV})$ with $60-650 \mathrm{~m} / \mathrm{z}$ scanning range. Five biological replicates were included for each assay. For each biological replicate, mature inflorescence stems of 20 individual plants were pooled and assayed.

\section{Microscope image acquisition}

Confocal imaging was performed using a Leica TCS SP2 confocal microscope (Leica Microsystems) and the HCX PL APO $63 \times / 1.2 \mathrm{~W}$ water-immersion objective. All images were analyzed using Leica Confocal Software. GFP channels were acquired by scanning sections using the 488-nm laser line for excitation. Emission of the GFP signal was detected between 500 and $530 \mathrm{~nm}$. Microscopy of vascular tissues was carried out after preparing $100 \mu \mathrm{m}$ longitudinal sections of 35-day-old fresh stem tissues using Vibratome 1000 plus. GUS staining was performed on 35-day-old stem tissues and 7-day-old whole seedlings as described in Srivastava et al. [26].

\section{Affymetrix microarray and qRT-PCR analysis}

The Affymetrix arrays and qRT-PCR experiments were performed using total RNA from 35-day-old inflorescence stem basal portion. Three biological replicates were included for both wild-type control and fpgs 1 mutant and each replicate had ten pooled plants. Total RNA was isolated using an RNeasy Mini Kit (Qiagen, Valencia, CA). RNA quantification and QC was as described previously [81]. For each array experiment, $500 \mathrm{ng}$ of total RNA was used for labeling using the Affymetrix GeneChip ${ }^{\circledR}$ Arabidopsis ATH1 Genome Array (Affymetrix, Santa Clara, CA). Probe labeling, chip hybridization, and scanning were performed according to the manufacturer's instructions for IVT Express Labeling Kit (Affymetrix). Data normalization and analysis were conducted as described earlier [81]. The microarray data were submitted to ArrayExpress and the accession no. is E-MEXP-3915.

Real-time qRT-PCR was performed using previously described procedures [26]. The plant-specific EF4A2 (At1g54270) gene was used as a control for constitutive gene expression. The primers used for this analysis are presented in Additional file 9: Table S2. Three biological replicates and three technical replicates were used for each sample group.

\section{Analysis of AdoMet levels}

Two hundred mg lyophilized ground samples of wild type and the mutant stem tissue were put into $10 \mathrm{ml}$ ethanol: water $(70: 30 \mathrm{v} / \mathrm{v})$ mix and samples were centrifuged at $14,000 \mathrm{rpm}$ for $15 \mathrm{~min}$ at $4{ }^{\circ} \mathrm{C}$. Supernatant was collected and further processing and analysis of the sample were done as described by Castro et al. [37]. UPLC/FLR analysis of AdoMet derivatives was carried out using a Waters Acquity UPLC system (Waters) coupled to FLR detector (Waters). A Waters Acquity UPLC $2.1 \times 150 \mathrm{~mm}, \mathrm{BEH}$ $\mathrm{C} 18$ column was used for analysis at $20{ }^{\circ} \mathrm{C}$. The mobile phase consisted of $0.1 \mathrm{M}$ sodium acetate in HPLC grade water, $\mathrm{pH} 4.5$ (A), and HPLC grade acetonitrile (B). Using an injection volume of $2.0 \mu \mathrm{l}$, separation was achieved using the following gradient: isocratic at $95.8 \%$ A for $7.8 \mathrm{~min}$; $95.8 \%$ A to $50 \% \mathrm{~A}$ in $6 \mathrm{~min}$; isocratic at $50 \% \mathrm{~A}$ for $1 \mathrm{~min}$ followed by re-equilibration at $95.8 \%$ A for $7 \mathrm{~min}$ at a flow rate of $0.280 \mathrm{ml} / \mathrm{min}$. The fluorescent AdoMet derivatives were monitored at excitation of $270 \mathrm{~nm}$ and emission of $410 \mathrm{~nm}$ with a PMT Gain setting of 1.00 and data rate of $5 \mathrm{pts} / \mathrm{s}$.

A total of five biological replicates were used, and 20 plants in total were pooled for each replicate. Identification of compounds was based on retention time of authentic standards. Data were processed using Empower 2 Software (Waters).

\section{Preparation of glucuronoxylan oligosaccharides and ${ }^{1} \mathrm{H}$-NMR spectroscopy}

Alcohol insoluble residues (AIR) were obtained from 35-day-old inflorescence stems of wild-type and fpgs 1-1 mutant and treated sequentially with specific endoglycanases as described [82]. The enzyme-treated residue was then extracted with $1 \mathrm{~N} \mathrm{KOH}$ containing $1 \%(\mathrm{w} / \mathrm{v})$ $\mathrm{NaBH}_{4}$ and then with $4 \mathrm{~N} \mathrm{KOH}$ containing $1 \%$ (w/v) $\mathrm{NaBH}_{4}$. The 1 and $4 \mathrm{~N} \mathrm{KOH}$ soluble fractions were neutralized with glacial acetic acid, dialyzed against deionized water and lyophilized. Glucuronoxylan oligosaccharides were generated by treating the $1 \mathrm{~N} \mathrm{KOH}$ soluble fractions for $24 \mathrm{~h}$ at $37^{\circ} \mathrm{C}$ with a Trichoderma viride endoxylanase (M1, 0.04 units/10 mg polysaccharide; Megazyme).

The glucuronoxylan-derived oligosaccharides were characterized by ${ }^{1} \mathrm{H}$ NMR spectroscopy as described in Urbanowicz et al. [5]. Glucuronoxylan oligosaccharides $(1-2 \mathrm{mg})$ were dissolved in $\mathrm{D}_{2} \mathrm{O}(0.25 \mathrm{~mL}, 99.9 \%$; Cambridge Isotope Laboratories, Andover, MA). Oneand two-dimensional NMR spectra were recorded at $298^{\circ} \mathrm{K}$ with a Varian Inova-NMR spectrometer (Agilent Technologies, Santa Clara CA) operating at $600 \mathrm{MHz}$ for ${ }^{1} \mathrm{H}$ and equipped with a $5-\mathrm{mm}$ NMR cold probe as described [5]. Chemical shifts were measured relative to internal acetone $(\delta 2.225)$. Data were processed using 
MestReNova software (Universidad de Santiago de Compostela, Spain). The extent of GlcA methylation was determined by integration of the signals corresponding to the anomeric protons of GlcA and methylated GlcA in the 1D NMR spectra. The areas of the overlapping signals were determined using the deconvolution method in MestReNova. The degree of GlcA $O$-methylation was calculated using the data obtained in the NMR analysis of GX oligosaccharides obtained by two independent endoxylanase treatments.

\section{Glycome profiling and immunofluorescence labeling}

Preparation of cell wall AIR, cell wall fractionation, and glycome profiling were carried out as described previously [83, 84]. Plant glycan-directed monoclonal antibodies [85]; Additional file 10: Appendix S1) were obtained as hybridoma cell culture supernatants from laboratory stocks at the Complex Carbohydrate Research Center [CCRC, JIM, and MAC series; available from CarboSource Services (http://www.carbosource.net)]. For immuno-labeling experiments, 35-day-old stem from both wild type and fgps1-1 were fixed, sectioned, and immunolabeled as described by Avci et al. [86].

\section{Determination of saccharification efficiency}

Cell-wall residues (CWRs) used in lignin analysis were also used for sugar analyses as described previously [70, 71] with slight modifications. Enzymatic saccharification of Arabidopsis samples (with and without acid pre-treatment) was performed following the analytical procedure of the National Renewable Energy Laboratory (LAP-009) (http://www.nrel.gov/biomass/analytical_procedures. html). To release total sugar in the medium, $100 \mathrm{mg}$ CWR was incubated at $30{ }^{\circ} \mathrm{C}$ for $1 \mathrm{~h}$ in $1.5 \mathrm{ml} 72 \%$ (w/v) $\mathrm{H}_{2} \mathrm{SO}_{4}$ and later autoclaved at $121{ }^{\circ} \mathrm{C}$ for $30 \mathrm{~min}$ after adding $42.5 \mathrm{ml}$ deionized water. The material was centrifuged at $4000 \mathrm{rpm}$ for $30 \mathrm{~min}$ and the supernatant was collected in a new tube followed by diluting the entire extract to $50 \mathrm{ml}$ with deionized water. For the saccharifications without pretreatment, $100 \mathrm{mg}$ CWR was directly incubated in $10 \mathrm{ml}$ digestion solution $(8.8 \mathrm{ml}$ $0.1 \mathrm{M}, \mathrm{pH}=4.8$ sodium citrate buffer $+0.2 \mathrm{ml} 2 \%$ $\mathrm{NaN}_{3}+1.0 \mathrm{ml}$ Enzyme Cocktail stock) at $50{ }^{\circ} \mathrm{C}$ for $72 \mathrm{~h}$. The enzyme cocktail stock was prepared using $1.5 \mathrm{ml}$ cellulase stock from Trichoderma reesei (Sigma-Aldrich, St. Louis, MO, USA) and $1.5 \mathrm{ml}$ Novozyme 188 stock Cellobiase from Aspergillus niger (Sigma-Aldrich) in $45.5 \mathrm{ml}$ sodium citrate buffer $(\mathrm{pH}=4.8)$. For pretreated samples, $100 \mathrm{mg}$ CWRs were pretreated with $2.5 \mathrm{ml}$ of $1.5 \%(\mathrm{w} / \mathrm{v}) \mathrm{H}_{2} \mathrm{SO}_{4}$ and these samples were autoclaved at $121{ }^{\circ} \mathrm{C}$ for $40 \mathrm{~min}$. This acid-pretreated material was washed three times with $10 \mathrm{ml}$ water to obtain neutral $\mathrm{pH}$ and after each washing, the material was centrifuged at $4000 \mathrm{rpm}$ for $20 \mathrm{~min}$ to retain any CWRs from the supernatant. The remaining biomass was lyophilized for $24 \mathrm{~h}$ and treated with enzyme cocktail as described earlier. Monomeric sugars (glucose and xylose) released in the samples were analyzed spectrophotometrically using the phenol-sulfuric acid assay method [87]. The concentration in the original sample was calculated with a standard curve based on known $D$-glucose concentrations (Sigma-Aldrich).

Saccharification efficiency was determined as the ratio of sugars released by enzymatic hydrolysis to the amount of sugars present in the cell wall material before enzymatic hydrolysis. For each biological replicate, mature inflorescence stems of 20 individual plants were pooled and assayed. Five biological replicates were included for each assay.

\section{High-throughput pretreatment and enzymatic hydrolysis (HTPH) and downscaled compositional analysis}

The HTPH system at University of California, Riverside [88-90] was employed to determine whether the mutants exhibited altered sugar release compared to the WT control during pretreatment and enzymatic hydrolysis. Glucose and xylose release from hydrothermal pretreatment and co-hydrolysis were measured. First, hydrothermal pretreatment was conducted at $180{ }^{\circ} \mathrm{C}$ for $11.1 \mathrm{~min}$. Then, the pretreated slurry was co-hydrolyzed $50{ }^{\circ} \mathrm{C}$ in $50 \mathrm{mM}$ citrate buffer ( $\mathrm{pH} 4.8$ ) for 72 h. Accellerase ${ }^{\circledR} 1500$ cellulase $(112.5 \mathrm{mg})$ and XY xylanase $(37.5 \mathrm{mg})$ from Genencor were used to release glucan and xylan in the raw biomass. Glucans and xylans were determined using a downscaled compositional analysis method [88] that is nearly identical to conventional wet chemistry procedures [90], but uses 100 times less biomass. The entire process was performed in $1.5 \mathrm{ml}$ high recovery glass vials (Agilent, Santa Clara, CA, USA) with $3 \mathrm{mg}$ dry biomass, loaded into each vial by a Core Module Robotics Platform (Symyx Technologies, Sunnyvale, CA). A set of glucose and xylose sugar recovery standards (SRS) were run in parallel for correction of sugar degradation. Sugars were analyzed by Waters Alliance 2695 HPLC (Milford, MA, USA) equipped with an Aminex HPX-87H column (BioRad, Hercules, CA, USA) and a refractive index detector. 


\section{Additional files}

Additional file 1: Fig. S1. Publicly available microarray data showing preferential expression of FPGS1 in vascular tissues. Data from Genevestigator (https://genevestigator.com/gv/).

Additional file 2: Fig. S2. Metabolite profiling in 7-day-old whole seedlings of wild type and fpgs 1-1. Results showing significant reduction in levels of lignin precursors and related compounds in the fpgs 1-1 mutant. Re-production permitted by Plant Physiology [26]. Each biological replicate was visualized in a single column (average of $n=3$ ). Alterations in mean phenolic acid levels of fpgs 1-1 compared with the wild type (Student's t test, ${ }^{*} P<0.05$ ).

Additional file 3: Table S1. Microarray analysis table of fpgs 1-1 and wildtype plants in 35-d-old stem of Arabidopsis.

Additional file 4: Fig. S3. Chromatographic profiles of wild-type and fpgs 1 stem tissue samples analyzed for AdoMet content. Analysis was according to Castro et al. [37].

Additional file 5: Table S3. mAbs detecting significant differences between wild-type and fpgs 1 mutants stem serial extracts.

Additional file 6: Fig. S4. Hydrothermal pretreatment releases more xylose and glucose from fpgs 1 biomass than from wild-type biomass. (A) Glucan and xylan contents of Arabidopsis wild-type and fpgs 1-1 stem biomass. (B) Total xylose (monomer plus oligomers) released by cellulase and xylanase (150 mg protein/g structural sugars in biomass) after hydrothermal pretreatment at $180^{\circ} \mathrm{C}$ for $11.1 \mathrm{~min}$. (C) Glucose and xylose released by cellulase and xylanase (150 mg protein/g structural sugars in biomass) without pretreatment. Error bars are $\mathrm{SE}, \mathrm{n}=4$

Additional file 7: Fig. S5. Comparative aerial growth analysis of fpgs mutants, complemented FPGS1 line (FPGS1C) and wild-type plant. The growth experiment included wild-type plant, two independent mutant lines of fpgs1 (fpgs 1-1 and fpgs 1-3), knockout mutant of other two isoforms of FPGS genes (fpgs2-mitochondiral and fpgs3-cytoplasmic) and complemented transgenic lines of fpgs 1-1 [FPGS1C (pFPGS1::FPGS1GFP:.fpgs 1-1)]. Samples were collected at 35 days after germination. Collectively no visual differences were observed in the above-ground growth of these plants (A). No significant differences were observed in per plant fresh weight (B) and dry biomass (C).

Additional file 8: Fig. S6. Schematic representation of C1 metabolism association with the monolignol biosynthetic pathway (Adapted from Humphreys and Chapple [91], Ravanel et al. [56]; van den Broeck et al. [16]. Arrows represent enzymatic reactions and abbreviations depicted next to arrows are the name of the enzyme that catalyzes the associated reaction. (PAL) L-Phenylalanine ammonia lyase; $(\mathrm{C} 4 \mathrm{H})$ Cinnamate 4-hydroxylase; (4-CL) 4-coumarate:coenzyme A ligase; (CCR) Cinnamoyl-CoA reductase; (HCT) Hydroxycinnamoyl CoA: shikimate hydroxycinnamoyltransferase; $\left(\mathrm{C}^{\prime} \mathrm{H}\right)$ 4-Coumaroyl-shikimate 3'-hydroxylase; (CCoAOMT) CaffeoylCoA-3-O-methyltransferase; (CAD) Cinnamyl alcohol dehydrogenase; (Lac 4) Laccase 4; (F5H) Ferulate 5-hydroxylase; (COMT) Caffeic acid 3-O-methyltransferase; (FPGS1) Folypolyglutamate synthetase 1; (SHMT) Serine hydroxymethyltransferase; (5,10-Met-THF) 5,10-Methylenetetrahydrofolate reductase; (Met-Syn) Methionine synthase; (SAM-Syn) S-Adenosyl methionine-Synthase; (SAM-MT) S-Adenosyl methionine dependent Methyl transferase; (SAM-HCT) S-adenosyl homocysteinase; (SAHH) S-Adenosyl-L-homocysteine hydrolase; (Cys) Cysteine; (Cys-Syn) Cystathionine synthase; (Cys-Lys) Cystayhioninelyase.

Additional file 9: Table S2. Primer sequences used for genotyping, plasmid construction, and gene expression analysis by qRT-PCR.

Additional file 10: Appendix S1. List of cell wall monoclonal antibodies.

\section{Abbreviations}

AdoMet: S-adenosyl L-methionine; AIR: alcohol insoluble residues; AtGXMT1: Arabidopsis glucuronoxylan methyltransferase 1; C1: one-carbon; CCOAOMT: Caffeoyl-COA 3-O-methyltransferase; CCRC: Complex Carbohydrate Research
Center; CWR: cell wall residue; FPGS: folylpolyglutamate synthetase; GFP: green fluorescent protein; GUS: $\beta$-glucuronidase; GX: 4-O-methyl glucuronoxylan; HMT: Hcy S-methyltransferase; SAMS: S-adenosylmethionine synthetase; SULTR: sulphate transporter.

\section{Authors' contributions}

AS was involved in experimental design, plant growth and phenotype analysis, GUS and GFP transgenic analysis, lignin analysis, AdoMet quantification, manuscript drafting; EB was involved in experimental design, GUS and GFP transgenic analysis and manuscript drafting; $Y T$ was involved in experimental design, collaboration communications, microarray and real-time qRT-PCR analysis and manuscript drafting; FC and RD were involved in lignin quantifications, data analysis and interpretation as well as manuscript drafting; TR was involved in real-time qRT-PCR experiments primer design, data generation and data analysis as well as manuscript drafting; SP and JSM were involved in glycome profiling-related data analysis, data interpretation and manuscript drafting; UA was involved in immunolocalization-related data analysis, data interpretation and manuscript drafting; MGH was involved in glycome profiling and immunolocalization data analysis and interpretation and manuscript drafting; MJP, BU, JB and WY were involved in characterizing glucuronoxylanderived oligosaccharide-related data generation, data analysis and interpretation as well as manuscript drafting; $\mathrm{HL}$ and CEW were involved in HTPH and downscaled compositional analysis, data analysis and interpretation as well as manuscript drafting; DVH, MB and LWS were involved in metabolites measurement, AdoMet quantification, data analysis and interpretation as well as manuscript drafting. All authors read and approved the final manuscript.

\section{Author details}

${ }^{1}$ Plant Biology Division, The Samuel Roberts Noble Foundation, Ardmore, OK 73401, USA. ${ }^{2}$ BioEnergy Science Center, United States Department of Energy, Oak Ridge, TN 37831, USA. ${ }^{3}$ Complex Carbohydrate Research Center, University of Georgia, 315 Riverbend Road, Athens, GA 30602, USA. ${ }^{4}$ Department of Plant Biology, University of Georgia, Athens, GA 30602, USA. ${ }^{5}$ Center for Environmental Research and Technology (CE-CERT), Bourns College of Engineering, University of California, Riverside, CA 92507, USA. ${ }^{6}$ Department of Biological Sciences, University of North Texas, Denton, TX 76203, USA.

\section{Acknowledgements}

The research described in this paper was carried out under the support of the BioEnergy Science Center (BESC, a U.S. Department of Energy Bioenergy Research Center supported by the Office of Biological and Environmental Research in the DOE Office of Science, U.S. Department of Energy) and also funded by the Samuel Roberts Noble Foundation. The authors thank Chunxiang Fu for critical reading of the manuscript and technical assistance with sugar analysis and Stacy Allen for assistance with array data generation. The generation of the CCRC series of glycan-directed monoclonal antibodies used in this work was supported by the NSF Plant Genome Program (DBI-0421683; IOS-0923992).

\section{Competing interests}

The authors declare that they have no competing interests.

Received: 23 July 2015 Accepted: 30 November 2015

Published online: 21 December 2015

\section{References}

1. Appling DR. Compartmentation of folate-mediated one-carbon metabolism in eukaryotes. FASEB J. 1991;5:2645-51.

2. Rébeillé F, Ravanel S, Jabrin S, Douce R, Storozhenko S, Van Der Straeten D. Folates in plants: biosynthesis, distribution, and enhancement. Physiol Plant. 2006;126:330-42.

3. Hanson AD, Roje S. One-carbon metabolism in higher plants. Annu Rev Plant Biol. 2001;52:119-37.

4. Eckardt NA. Gibberellins are modified by methylation in planta. Plant Cell. 2007;19:3-6.

5. Urbanowicz BR, Pena MJ, Ratnaparkhe S, Avci U, Backe J, Steet HF, Foston M, Li HJ, O’Neill MA, Ragauskas AJ, Darvill AG, Wyman C, Gilbert HJ, York 
WS. 4-O-methylation of glucuronic acid in Arabidopsis glucuronoxylan is catalyzed by a domain of unknown function family 579 protein. Proc Natl Acad Sci USA. 2012;109:14253-8.

6. Zhong R, lii WH, Negrel J, Ye ZH. Dual methylation pathways in lignin biosynthesis. Plant Cell. 1998;10:2033-46.

7. Whetten R, Sederoff R. Lignin biosynthesis. Plant Cell. 1995;7:1001-13.

8. Petersen M, Strack D, Matern U. Biosynthesis of phenyl-propanoids and related compounds. In: Wink M, editor. Biochemistry of plant secondary metabolism. Sheffield: Sheffield Academic Press; 1999. p. 151-221.

9. Zhong R, Ye ZH. Transcriptional regulation of lignin biosynthesis. Plant Signal Behav. 2009;4:1028-34

10. Zhao Q, Dixon RA. Transcriptional networks for lignin biosynthesis: more complex than we thought? Trend Plant Sci. 2011;16:227-33.

11. Vanholme R, Cesarino I, Rataj K, Xiao Y, Sundin L, Goeminne G, Kim H, Cross J, Morreel K, Araujo P, Welsh L, Haustraete J, McClellan C, Vanholme B, Ralph J, Simpson GG, Halpin C, Boerjan W. Caffeoyl shikimate esterase (CSE) is an enzyme in the lignin biosynthetic pathway in Arabidopsis. Science. 2013;341:1103-6.

12. Bonawitz ND, Im KJ, Tobimatsu Y, Ciesielski PN, Anderson NA, Ximenes E, Nicholas D, Maeda J, Ralph J, Donohoe BS, Ladisch M, Chapple C. Disruption of Mediator rescues the stunted growth of a lignin-deficient Arabidopsis mutant. Nature. 2014;509:376-80.

13. Hao Z, Mohnen D. A review of xylan and lignin biosynthesis: foundation for studying Arabidopsis irregular xylem mutants with pleiotropic phenotypes. Crit Rev Biochem Mol Bio. 2014;49:212-41.

14. Li X, Weng JK, Chapple C. Improvement of biomass through lignin modification. Plant J. 2008;54:569-81.

15. Byerrum RU, Flokstra JH, Dewey $L$, Ball CD. Incorporation of formate and the methyl group of methionine into methoxyl groups of lignin. J Biol Chem. 1954;210:633-43.

16. Van den Broeck HC, Maliepaard C, Ebskamp MJM, Toonen MAJ, Koops AJ. Differential expression of genes involved in C1 metabolism and lignin biosynthesis in wooden core and bast tissues of fibre hemp (Cannabis sativa L.). Plant Sci. 2008;174:205-20.

17. Srivastava AC, Palanichelvam K, Ma J, Steele J, Blancaflor EB, Tang Y. Collection and analysis of expressed sequence tags derived from laser capture microdissected switchgrass (Panicum virgatum L. Alamo) vascular tissues. BioEnergy Res. 2010;3:278-94.

18. Villalobos DP, Díaz-Morenol SM, Said ES, Cañas RA, Osuna D, Van Kerckhovenl SHE, Bautista R, Claros MG, Cánovas FM, Cantón FR. Reprogramming of gene expression during compression wood formation in pine: coordinated modulation of S-adenosylmethionine, lignin and lignan related genes. BMC Plant Biol. 2012;12:100.

19. Shen B, Li C, Tarczynski MC. High free-methionine and decreased lignin content result from a mutation in the Arabidopsis S-adenosyl-L-methionine synthetase 3 gene. Plant J. 2002;29:371-80.

20. Tang HM, Liu S, Hill-Skinner S, Wu W, Reed D, Yeh CT, Nettleton D, Schnable PS. The maize brown midrib2 (bm2) gene encodes a methylenetetrahydrofolate reductase that contributes to lignin accumulation. Plant J. 2014;77:380-92.

21. Ebringerová A, Hromádková Z, Heinze T, Hemicellulose TH. Polysaccharides I. Adv Polym Sci. 2005;186:1-67.

22. Hanson AD, Gregory JF. Folate biosynthesis, turnover, and transport in plants. Annu Rev Plant Biol. 2011;62:105-25.

23. Shane B. Folylpolyglutamate synthesis and role in the regulation of onecarbon metabolism. Vitam Horm. 1989;45:263-335.

24. Mehrshahi P, Gonzalez-Jorge S, Akhtar TA, Ward JL, Santoyo-Castelazo A, Marcus SE, Lara-Núñez A, Ravanel S, Hawkins ND, Beale MH, Barrett DA, Knox JP, Gregory JF 3rd, Hanson AD, Bennett MJ, Dellapenna D. Functional analysis of folate polyglutamylation and its essential role in plant metabolism and development. Plant J. 2010;64:267-79.

25. Akhtar TA, Orsomando G, Mehrshahi P, Lara-Núñez A, Bennett MJ, Gregory JF III, Hanson AD. A central role for gamma-glutamyl hydrolases in plant folate homeostasis. Plant J. 2010;64:256-66

26. Srivastava AC, Ramos-Parra PA, Bedair M, Robledo-Hernández AL, Tang Y, Sumner LW, de la Garza RID, Blancaflor EB. The folylpolyglutamate synthetase plastidial isoform is required for postembryonic root development in Arabidopsis. Plant Physiol. 2011;155:1237-51.

27. Ravanel S, Cherest H, Jabrin S, Grunwald D, Surdin-Kerjan Y, Douce R, Rébeillé F. Tetrahydrofolate biosynthesis in plants: molecular and functional characterization of dihydrofolate synthetase and three isoforms of folylpolyglutamate synthetase in Arabidopsis thaliana. Proc Natl Acad Sci USA. 2001;98:15360-5.

28. Jiang L, Liu Y, Sun H, Han Y, Li J, Li C, Guo W, Meng H, Li S, Fan Y, Zhang C. The mitochondrial folylpolyglutamate synthetase gene is required for nitrogen utilization during early seedling development in Arabidopsis. Plant Physiol. 2013;161:971-89.

29. Zhou HR, Zhang FF, Ma ZY, Huang HW, Jiang L, Cai T, Zhu JK, Zhang C, He XJ. Folate polyglutamylation is involved in chromatin silencing by maintaining global DNA methylation and histone H3K9 dimethylation in Arabidopsis. Plant Cell. 2013;25:2545-59.

30. Reyes-Hernández BJ, Srivastava AC, Ugartechea-Chirino Y, Shishkova S, Ramos-Parra PA, Lira-Ruan V, Díaz de la Garza RI, Dong G, Moon J-C, Blancaflor EB, Dubrovsky JG. The root indeterminacy-to-determinacy developmental switch is operated through a folate-dependent pathway in Arabidopsis thaliana. New Phytol. 2014;202:1223-36.

31. Meng H, Jiang L, Xu B, Guo W, Li J, Zhu X, Qi X, Duan X, Meng X, Fan Y, Zhang C. Arabidopsis plastidial folylpolyglutamate synthetase is required for seed reserve accumulation and seedling establishment in darkness. PLoS One. 2014;9:e101905.

32. Li L, Skinner SH, Liu S, Beuchle D, Tang HM, Yeh C-T, Nettleton D, Schnable PS. The maize brown midrib4 (bm4) gene encodes a functional folylpolyglutamate synthase. Plant J. 2015;81:493-504.

33. Srivastava AC, Tang Y, Diaz Garza Rl, Blancaflor EB. The plastidial folylpolyglutamate synthetase and root apical meristem maintenance. Plant Signal Behav. 2011;6:751-4.

34. Zimmermann P, Hirsch-Hoffmann M, Hennig L, Gruissem W. GENEVESTIGATOR. Arabidopsis microarray database and analysis toolbox. Plant Physiol. 2004;136:2621-32.

35. Costa MA, Collins RE, Anterola AM, Cochrane FC, Davin LB, Lewis NG. An in silico assessment of gene function and organization of the phenylpropanoid pathway metabolic networks in Arabidopsis thaliana and limitations. Phytochem. 2003;64:1097-112.

36. Boerjan W, Bauw G, Van MM, Inze D. Distinct phenotypes generated by overexpression and suppression of S-adenosyl-L-methionine synthetase reveal developmental patterns of gene silencing in tobacco. Plant Cell. 1994;6:1401-14.

37. Castro R, Struys EA, Jansen EE, Blom HJ, de Almeida IT, Jakobs C. Quantification of plasma S-adenosylmethionine and S-adenosylhomocysteine as their fluorescent 1, N6-etheno derivatives:an adaptation of previously described methodology. J Pharm Biomed Anal. 2002;29:963-8.

38. Shen $H, H e X$, Poovaiah CR, Wuddineh WA, Ma J, Mann DGJ, Wang H, Jackson L, Tang Y, Jr Neal Stewart, Chen F, Dixon RA. Functional characterization of the switchgrass (Panicum virgatum) R2R3-MYB transcription factor PVMYB4 for improvement of lignocellulosic feedstocks. New Phytol. 2012;193:121-36.

39. Chen F, Dixon RA. Lignin modification improves fermentable sugar yields for biofuel production. Nature Biotech. 2007;25:759-61.

40. Li X, Wu H, Southerton S. Comparative genomics reveals conservative evolution of the xylem transcriptome in vascular plants. BMC Evol Biol. 2010;10:190.

41. Vanholme R, Storme V, Vanholme B, Sundin L, Christensen JH, Goeminne G, Halpin C, Rohde A, Morreel K, Boerjan W. A systems biology view of responses to lignin biosynthesis perturbations in Arabidopsis. Plant Cell. 2012;24:3506-29.

42. Van Acker R, Vanholme R, Storme V, Mortimer JC, Dupree P, Boerjan W. Lignin biosynthesis perturbations affect secondary cell wall composition and saccharification yield in Arabidopsis thaliana. Biotechnol Biofuels. 2013;6:46.

43. VandenBosch KA, Bradley DJ, Knox JP, Perotto S, Butcher GW, Brewin NJ. Common components of the infection thread matrix and the intercellular space identified by immunocytochemical analysis of pea nodules and uninfected roots. EMBO J. 1989;8:335-42.

44. Knox JP, Linstead PJ, King J, Cooper C, Roberts K. Pectin esterification is spatially regulated both within cell walls and between developing tissues of root apices. Planta. 1990;181:512-21.

45. Grabber JH, Santoro N, Foster CE, Elumalai S, Ralph J, Pan X. Incorporation of flavonoid derivatives or pentagalloyl glucose into lignin enhances cell wall saccharification following mild alkaline or acidic pretreatments. Bioenergy Res. 2015;8:1391-400.

46. Loqué D, Scheller HV, Pauly M. Engineering of plant cell walls for enhanced biofuel production. Curr Opin Plant Biol. 2015;25:151-61. 
47. Muñiz L, Minguet EG, Singh SK, Pesquet E, Vera-Sirera F, Moreau-Courtois CL, Carbonell J, Blázquez MA, Tuominen H. ACAULIS5 controls Arabidopsis xylem specification through the prevention of premature cell death. Development. 2008;135:2573-82.

48. Ye ZH, Kneusel RE, Matern U, Varner JE. An alternative methylation pathway in lignin biosynthesis in Zinnia. Plant Cell. 1994;6:1427-39.

49. Ye ZH, Zhong R, Morrison WH, Himmelsbach D. Caffeoyl coenzyme A O-methyltransferase and lignin biosynthesis. Phytochem. 2001;57:1177-85.

50. Atanassova R, Favet N, Martz F, Chabbert B, Tollier MT, Monties B, Fritig B, Legrand $\mathrm{M}$. Altered lignin composition in transgenic tobacco expressing 0 -methyltransferase sequences in sense and antisense orientation. Plant J. 1995;8:465-77.

51. Guo D, Chen F, Inoue K, Blount JW, Dixon RA. Downregulation of caffeic acid 3-O-methyltransferase and caffeoyl COA 3-O-methyltransferase in transgenic alfalfa. Impacts on lignin structure and implications for the biosynthesis of $\mathrm{G}$ and S lignin. Plant Cell. 2001;13:73-88.

52. Do C-T, Pollet B, Thévenin J, Sibout R, Denoue D, Barrière Y, Lapierre C, Jouanin L. Both caffeoyl coenzyme A 3-O-methyltransferase 1 and caffeic acid $O$-methyltransferase 1 are involved in redundant functions for lignin, flavonoids and sinapoyl malate biosynthesis in Arabidopsis. Planta. 2007:226:1117-29.

53. Ranocha P, McNeil SD, Ziemak MJ, Li C, Tarczynski MC, Hanson AD. The S-methylmethionine cycle in angiosperms: ubiquity, antiquity and activity. Plant J. 2001;25:575-84.

54. Whitfield CD, Steers EJ, Weissbach H. Purification and properties of 5-methyltetrahydropteroyltriglutamate-homocysteine transmethylase. J Biol Chem. 1970;245:390-401.

55. Cherest H, Thomas D, Surdin-Kerjan Y. Polyglutamylation of folate coenzymes is necessary for methionine biosynthesis and maintenance of intact mitochondrial genome in Saccharomyces cerevisiae. J Biol Chem. 2000;275:14056-63.

56. Ravanel SP, Block MA, Rippert $P$, Jabrin S, Curien G, Rébeillé F, Douce R. Methionine metabolism in plants. J Biol Chem. 2004;279:22548-57.

57. Bonawitz ND, Chapple C. The genetics of lignin biosynthesis: connecting genotype to phenotype. Annu Rev Gene. 2010;44:337-63.

58. Anterola AM, Lewis NG. Trends in lignin modification: a comprehensive analysis of the effects of genetic manipulations/mutations on lignification and vascular integrity. Phytochem. 2002;61:221-94.

59. Meyermans H, Morreel K, Lapierre C, Pollet B, De Bruyn A, Busson R, Herdewijn P, Devreese B, Van Beeumen J, Marita JM, Ralph J, Chen C, Burggraeve B, Van Montagu M, Messens E, Boerjan W. Modifications in lignin and accumulation of phenolic glucosides in poplar xylem upon down-regulation of caffeoyl-coenzyme A O-methyltransferase, an enzyme involved in lignin biosynthesis. J Biol Chem. 2000;275:36899-909.

60. Chen F, Kota P, Blount JW, Dixon RA. Chemical syntheses of caffeoyl and $5-\mathrm{OH}$ coniferyl aldehydes and alcohols and determination of lignin 0 -methyltransferase activities in dicot and monocot species. Phytochem. 2001;58:1035-42

61. Guo D, Chen F, Wheeler J, Winder J, Selman S, Peterson M, Dixon RA. Improvement of in-rumen digestibility of alfalfa forage by genetic manipulation of lignin O-methyltransferases. Transgenic Res. 2001;10:457-64.

62. Parvathi K, Chen F, Guo D, Blount JW, Dixon RA. Substrate preferences of O-methyltransferases in alfalfa suggest new pathways for 3-O-methylation of monolignols. Plant J. 2001;25:193-202.

63. Pinjion G, Maury S, Hoffmann L, Geoffroy P, Lapierre C, Pollet B, Legrand $M$. Repression of $O$-methyltransferase genes in transgenic tobacco affects lignin synthesis and plant growth. Phytochem. 2001;57:1167-76.

64. Loizeau K, De Brouwer V, Gambonnet B, Yu A, Renou JP, Van Der Straeten D, Lambert WE, Rebeille F, Ravanel SA. Genome-wide and metabolic analysis determined the adaptive response of Arabidopsis cells to folate depletion induced by methotrexate. Plant Physiol. 2008;148:2083-95.

65. Gigolashvili T, Kopriva S. Transporters in plant sulfur metabolism. Front Plant Sci. 2014;5:1-16.

66. Sauter M, Moffatt B, Saechao MC, Hell R, Wirtz M. Methionine salvage and S-adenosylmethionine: essential links between sulfur, ethylene and polyamine biosynthesis. Biochem J. 2013;451:145-54

67. Nikiforova VJ, Kopka J, Tolstikov V, Fiehn O, Hopkins L, Hawkesford MJ, Hesse H, Hoefgen R. Systems rebalancing of metabolism in response to sulfur deprivation, as revealed by metabolome analysis of Arabidopsis plants. Plant Physiol. 2005;138:304-18.
68. Yatusevich R, Mugford SG, Matthewman C, Gigolashvili T, Frerigmann H, Delaney S, Koprivova A, Flügge UI, Kopriva S. Genes of primary sulfate assimilation are part of the glucosinolate biosynthetic network in Arabidopsis thaliana. Plant J. 2010;62:1-11.

69. Lee C, Teng Q, Zhong R, Yuan Y, Haghighat M, Ye Z-H. Three Arabidopsis DUF579 domain-containing GXM proteins are methyltransferases catalyzing 4-O-methylation of glucuronic acid on xylan. Plant Cell Physiol. 2012;53:1934-49.

70. Fu C, Mielenz JR, Xiao X, Ge Y, Hamilton CY, Rodriguez M, Chen F, Foston M, Ragauskas A, Bouton J, Dixon RA, Wang ZY. Genetic manipulation of lignin reduces recalcitrance and improves ethanol production from switchgrass. Proc Natl Acad Sci USA. 2011;108:3803-8.

71. Fu C, Xiao X, Xi Y, Ge Y, Chen F, Bouton J, Dixon RA, Wang ZY. Downregulation of cinnamyl alcohol dehydrogenase (CAD) leads to improved saccharification efficiency in switchgrass. BioEnergy Res. 2011;4:153-64.

72. Tschaplinski TJ, Standaert RF, Engle NL, Martin MZ, Sangha AK, Parks JM, Smith JC, Samuel R, Jiang N, Pu Y, Ragauskas AJ, Hamilton CY, Fu C, Wang ZY, Davison BH, Dixon RA, Mielenz JR. Down-regulation of the caffeic acid O-methyltransferase gene in switchgrass reveals a novel monolignol analog. Biotechnol Biofuels. 2012;5:71.

73. Berthet S, Demont-Caulet N, Pollet B, Bidzinski P, Cézard L, Le Bris P, Borrega $\mathrm{N}$, Hervé J, Blondet $\mathrm{E}$, Balzergue $\mathrm{S}$. Disruption of LACCASE4 and 17 results in tissue-specific alterations to lignification of Arabidopsis thaliana stems. Plant Cell. 2011;23:1124-37.

74. Fornalé S, Capellades M, Encina A, Wang K, Irar S, Lapierre C, Ruel K, Joseleau J-P, Berenguer J, Puigdomènec P. Altered lignin biosynthesis improves cellulosic bioethanol production in transgenic maize plants down-regulated for cinnamyl alcohol dehydrogenase. Mol Plant. 2012;5:817-30.

75. Jung JH, Fouad WM, Vermerris W, Gallo M, Altpeter F. RNAi suppression of lignin biosynthesis in sugarcane reduces recalcitrance for biofuel production from lignocellulosic biomass. Plant Biotech J. 2012;10:1067-76.

76. Bouvier d'Yvoire M, Bouchabke-Coussa O, Voorend W, Antelme S, Cézard L, Legée F, Lebris P, Legay S, Whitehead C, McQueen-Mason SJ. Disrupting the cinnamyl alcohol dehydrogenase 1 gene (BdCAD1) leads to altered lignification and improved saccharification in Brachypodium distachyon. Plant J. 2013;73:496-508.

77. Curtis MD, Grossniklaus U. A gateway cloning vector set for highthroughput functional analysis of genes in planta. Plant Physiol. 2003;133:462-9.

78. Clough SJ, Bent AF. Floral dip: a simplified method for Agrobacteriummediated transformation of Arabidopsis thaliana. Plant J. 1998;16:735-43.

79. Hatfield R, Grabber J, Ralph J, Brei K. Using the acetyl bromide assay to determine lignin concentrations in herbaceous plants: some cautionary notes. J Agric Food Chem. 1999;47:628-32.

80. Lapierre C, Pollet B, Rolando C. New insights into the molecular architecture of hardwood lignins by chemical degradative methods. Res Chem Intermed. 1995;21:397-412.

81. Benedito VA, Torres-Jerez I, Murray J, Andriankaja A, Allen NS, Kakar K, Wandrey M, Verdier J, Zuber H, Ott T, Moreau S, Niebel A, Frickey T, Weiller G, He J, Dai X, Zhao PX, Tang Y, Udvardi MK. A gene expression atlas of the model legume Medicago truncatula. Plant J. 2008;55:504-13.

82. Peña MJ, Zhong R, Zhou G-K, Richardson EA, O'Neill MA, Darvill AG, York WS, Ye Z-H. Arabidopsis irregular xylem8 and irregular xylem9: implications for the complexity of glucuronoxylan biosynthesis. Plant Cell. 2007;19:549-63.

83. Pattathil S, Avci U, Miller JS, Hahn MG. Immunological approaches to plant cell wall and biomass characterization: glycome profiling. In: Himmel M, editor. Methods in molecular biology, biomass conversion: methods and protocols, vol. 908. New York: Springer Science Business Media; 2012. p. 61-72.

84. Pattathil S, Saffold T, Gallego-Giraldo L, O'Neill M, York WS, Dixon RA, Hahn MG. Changes in cell wall carbohydrate extractability are correlated with reduced recalcitrance of HCT downregulated alfalfa biomass. Ind Biotech. 2012:8:217-21.

85. Pattathil S, Avci U, Baldwin D, Swennes AG, McGill JA, Popper Z, Bootten T, Alber A, Davis RH, Chennareddy C, Dong R, O'She B, Rossi R, Leoff C, Freshour G, Narra R, O'Neil M, York WS, Hahn MG. A comprehensive toolkit of plant cell wall glycan-directed monoclonal antibodies. Plant Physiol. 2010;153:514-25. 
86. Avci U, Pattathil S, Hahn MG. Immunological approaches to plant cell wall and biomass characterization: immunolocalization of glycan epitopes. In: Himmel M, editor. Methods in molecular biology, biomass conversion: methods and protocols, vol. 908. New York: Springer; 2012. p. 73-82

87. Dubois M, Gilles KA, Hamilton JK, Rebers P, Smith F. Colorimetric method for determination of sugars and related substances. Anal Chem. 1956;28:350-6.

88. DeMartini JD, Studer MH, Wyman CE. Small-scale and automatable high-throughput compositional analysis of biomass. Biotechnol Bioeng. 2011;108:306-12.
89. Studer MH, DeMartini JD, Brethauer S, McKenzie HL, Wyman CE. Engineering of a high-throughput screening system to identify cellulosic biomass, pretreatments, and enzyme formulations that enhance sugar release. Biotech Bioeng. 2010;105:231-8.

90. Sluiter A, Hames B, Ruiz R, Scarlata C, Sluiter J, Templeton D, Crocker D. Determination of structural carbobydrates and lignin in biomass. In: Laboratory Analytical Procedure (LAP), NREL/TP-510-42618. Golden, CO, USA: National Renewable Energy Laboratory; 2008.

91. Humphreys JM, Chapple C. Rewriting the lignin roadmap. Curr Opin Plant Biol. 2002;5:224-9.

\section{Submit your next manuscript to BioMed Central} and we will help you at every step:

- We accept pre-submission inquiries

- Our selector tool helps you to find the most relevant journal

- We provide round the clock customer support

- Convenient online submission

- Thorough peer review

- Inclusion in PubMed and all major indexing services

- Maximum visibility for your research

Submit your manuscript at www.biomedcentral.com/submit

() BioMed Central 